\title{
El estilo político de la clase parlamentaria española: Propuesta metodológica para su estudio mediante análisis de contenido del Diario de Sesiones del Congreso de los Diputados (Comisiones) *
}

\author{
Raquel Pastor Yuste \\ Universidad Pablo de Olavide \\ rpasyus@dts.upo.es
}

\section{INTRODUCCIÓN}

\subsection{Género y élites políticas: Las diferencias de estilo}

Uno de los temas que viene ocupando recientemente la agenda de investigación en torno a las élites políticas se refiere al estilo político, si bien es un asunto que ha recibido, al menos en el caso de España, escasa atención teórica y sobre todo empírica (Uriarte, 1997).

Respecto a este tema, en el marco de la filosofía política contemporánea viene desarrollándose cierto debate en torno al «proyecto moral» que caracteriza y distingue a las mujeres frente a los varones. De manera resumida se sostiene que la división moral del trabajo en razón del género que tiene lugar mediante los procesos[[ de socialización, articulada en torno a los ámbitos doméstico y público (Fraser y Gordon, 1992) ha dado lugar al desarrollo de dos éticas diferentes, dos modos de razonamiento moral; a saber: la "ética del cuidado», propia del género femenino, centrada en las relaciones personales y la atención y cuidado de los demás, y la «ética de la justicia», propia de los varones, preocupada por la discusión sobre criterios de justicia y derechos desde una perspectiva universalista (Waerness, 1987; Kymlicka, 1995: 287-315). De tal manera que cualquier asunto moral por el que se interesen los hombres, tendería a ser reducido a la categoría de un asunto de «justicia y derechos», mientras que las preocupaciones morales de las mujeres se incluirían dentro de las categorías de «relaciones personales y del cuidado».

* En la realización de este artículo ha sido de gran ayuda las sugerencias y comentarios al texto realizadas por Clemente J. NAVARRO YANEZ. 
La diferencia entre ambos tipos de éticas se reflejaría en la esfera de la política, por un lado en agendas específicas según género, y por otro, en diferentes estilos de liderazgo.

Por lo que se refiere al primer aspecto, la literatura existente al respecto, viene señalando que las mujeres tienen frente a los varones una agenda política específica. De manera resumida se caracterizaría por una mayor atención a los aspectos relacionados con el ámbito de la reproducción, tal y como la familia, la salud, la vivienda o el bienestar social además de las políticas de acción positiva de género o minorías; mientras que la agenda de los varones se centraría en temas relacionados con el ámbito de la producción, esto es, mercado de trabajo, comunicaciones, políticas fiscales, defensa, infraestructuras, etc. En este sentido, se señala que las mujeres en el ejercicio de su actividad política tenderían a presentar mayor apoyo a iniciativas relacionadas con los derechos de las mujeres, y a presentar con mayor frecuencia proposiciones de ley o a formular preguntas parlamentarias en el área de la reproducción (respecto de la familia, salud, vivienda, medio ambiente y política del consumidor) mientras que los hombres tenderían a presentar preguntas relacionadas con la producción (esto es, mercado de trabajo, comunicaciones, políticas fiscales y energía). De tal manera que cabría hablar de divisiones de género en la actividad parlamentaria en términos de presentación de mociones, preguntas, e incluso, discursos parlamentarios.

Por otra parte, se sostiene que en el ejercicio de sus funciones parlamentarias, hombres y mujeres desarrollan estilos de liderazgo diferenciados, donde el estilo masculino se caracterizaría por una actitud dominante, asertiva y competitiva, mientras que el de las mujeres tendería a basarse en las relaciones.

En este sentido investigadores como Astin y Lelan (1991) consideran que hombres y mujeres ejercen estilos de liderazgo muy distintos, ya que los hombres utilizan un estilo de «liderazgo duro» que pone el acento sobre la jerarquía, la dominación y el orden, mientras que las mujeres ejercen un tipo de «liderazgo suave» caracterizado por la cooperación, la influencia y la autoridad.

En esta misma línea, Mary Robinson, quien fuera presidenta de Irlanda, sostiene que existen importantes diferencias entre el liderazgo femenino y el masculino «creo que las mujeres son instintivamente menos jerárquicas [....] son muy abiertas, permisivas y participativas, y son capaces de alentar a cada individuo a tener un papel y a comprometerse. Y creo que es lo mismo cuando las mujeres están en posiciones de liderazgo. No tratan de ser tan jerárquicas, de reafirmarse como individuos, sino que más bien tratan de influir en los otros para orientarlos en determinados sentidos, y de aprovechar las energías en un sentido cooperativo... '.

Lo dicho hasta ahora en torno a los razonamientos morales según género y su traducción en el quehacer político, se recoge de manera resumida en la figura 1.

${ }^{1}$ Liswwood, L.A. (1995): Women World Leaders, London, Harper Collins. 


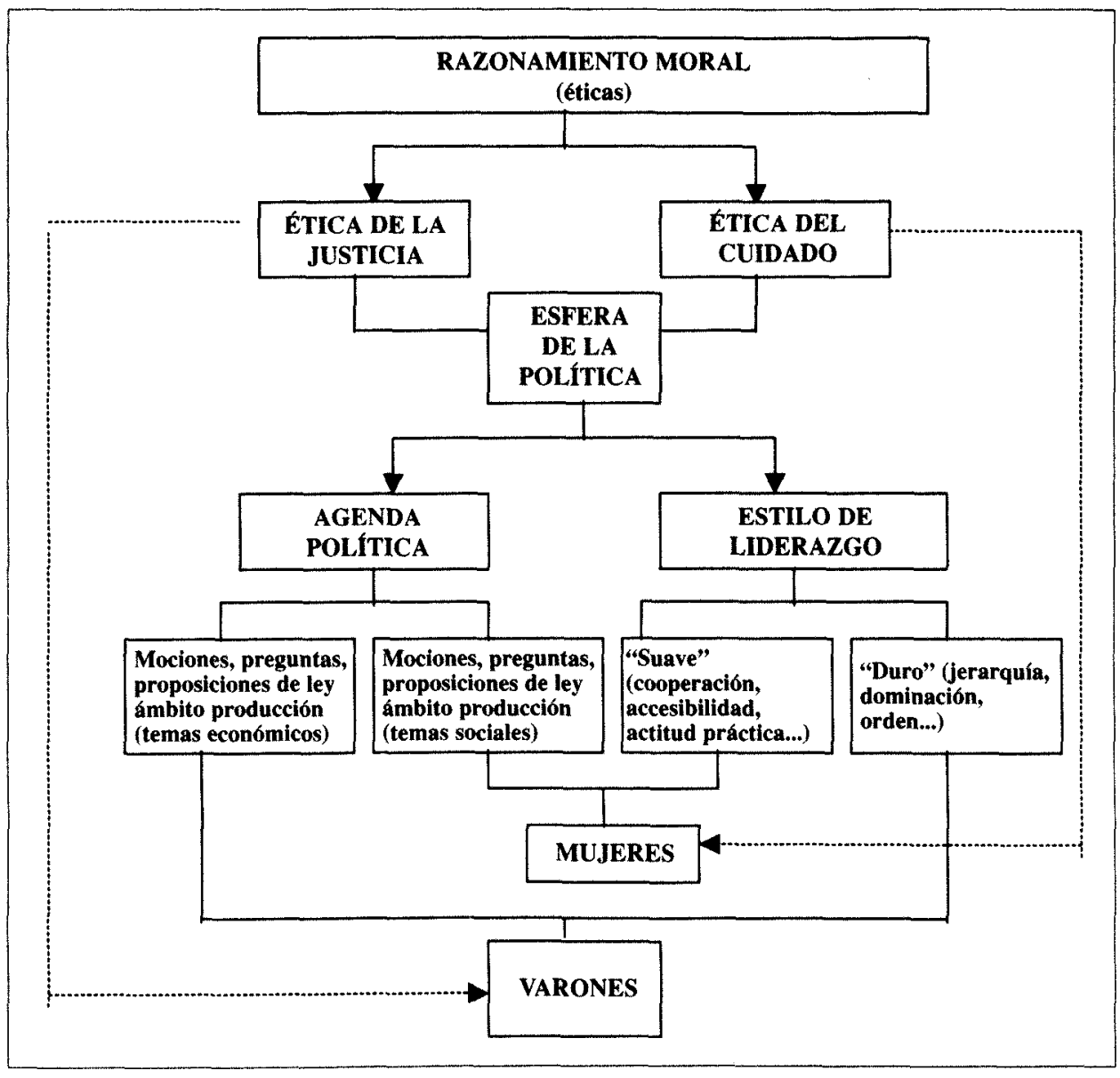

Figura 1. Agenda y estilo de liderazgo de la clase política según género

\subsection{El quehacer político: La propuesta de Dalherup}

Pese a lo comentado más arriba, hay que decir que no existe un acuerdo generalizado entre los investigadores en torno a la existencia de un estilo de liderazgo y agendas diferenciadas entre hombres y mujeres. De hecho hay autores que sostienen la inexistencia de tal diferencia, ya sea porque el factor más relevante es la pertenencia a un partido determinado -preferencias, cultura organizativa, etc...-, ya sea porque la agenda y el estilo político no es absoluto, derivado de una ética específica, sino contextual, en atención a variables de carácter institucional. De hecho, a partir de un estudio comparado sobre mujeres líderes nacionales que han estado al frente del gobierno de sus respectivos países, Michael Genovese (1997) señala que es dudoso que se pueda hablar de diferencias significativas en el estilo de liderazgo de hombres y mujeres. Considera que más que 
estilos diferentes de liderazgo lo que existen son situaciones diferentes, que requieren liderazgos diferentes, y el líder con éxito es aquel que reconoce y se adapta a esas situaciones. Se trataría de un «estilo flexible» con independencia del género, determinado por el contexto en el que los líderes deben de actuar.

En este sentido, y en el marco de la teoría de la «masa crítica» hay autores que sostienen que mientras que las mujeres se mantengan en una minoría, se harán evidentes pocas diferencias de género en los Parlamentos (Sapiro, 1981). La teoría de la masa crítica sugiere que la naturaleza de las interacciones entre los grupos depende de su tamaño. Cuando un grupo es claramente minoritario dentro de una sociedad, sus miembros desarrollan estrategias adaptativas, siguiendo las reglas y normas del grupo predominante. Pero una vez que el grupo alcanza un cierto tamaño, la teoría sostiene que habrá un cambio cualitativo en la naturaleza de las interacciones entre los grupos, puesto que la minoría comenzará a afirmarse y hacerse valer, con lo que podrá transformar la cultura institucional, las normas y valores predominantes.

Aplicando esta teoría a la posición de las mujeres en las instituciones políticas, Dalherup (1988) ha llamado la atención sobre la asociación entre presencia de la mujer en las sedes parlamentarias y la génesis y desarrollo de una agenda y un estilo político de género. En este sentido ha identificado cuatro tipo de situaciones: Los grupos homogéneos son totalmente dominados por un grupo mayoritario; los grupos sesgados tienen minorías por debajo del $15 \%$ del total de sus miembros, los grupos inclinados tienen minorías hasta un $40 \%$, y, finalmente, los grupos equilibrados presentan una relación entre subgrupos cercana a la mitad, en torno a 60:40. De este modo sostiene que cuando la composición de los Parlamentos se caracteriza por ser «grupos homogéneos» o «grupos sesgados», esto es, por la presencia mayoritaria de un grupo -los varones-, los grupos minoritarios -las mujeres-, desarrollarían estilos políticos y agendas de carácter adaptativo semejante a la de los grupos mayoritarios (los varones), pues para ingresar y ascender en la carrera política deben adoptar las normas y reglas institucionales que son marcadas por el grupo mayoritario -los varones-, a pesar de que puedan presentar prioridades o agendas similares. Sin embargo, cuando se da la situación de «grupos equilibrados» puede esperarse que los grupos minoritarios -las mujeres- se distancien de los mayoritarios en su quehacer político, tanto en su estilo de liderazgo como en su agenda. Si los Parlamentos se transformasen en su composición de grupos sesgados a inclinados, o incluso, equilibrados, podría transformarse la cultura institucional, el discurso político y la agenda política.

\section{LAS COMISIONES DEL CONGRESO DE LOS DIPUTADOS DE LA VII LEGISLATURA}

\subsection{Composición, cargos y trabajo político según género}

En este trabajo se trata de presentar una propuesta metodologica para el estudio del estilo político, y más en concreto, la agenda parlamentaria de la élite política Española de la VII legislatura, mediante Análisis de Contenido del Diario de Sesio- 
nes del Congreso de los Diputados (Comisiones), con el objeto de analizar la importancia de la presencia femenina en la actividad parlamentaria, tanto lo que se refiere a la génesis y desarrollo de una agenda específica como al papel que las élites políticas femeninas pudieran jugar en ello.

Por todo ello, parece conveniente realizar un primer acercamiento a la forma de hacer política que las parlamentarias españolas pudieran desarrollan frente a los varones y en cierta medida en los términos de la diferenciación entre la «ética del cuidado» y la «ética de la justicia» delimitados con anterioridad, dando cuenta de la estructura orgánica de la Cámara Baja, prestando especial atención a las Comisiones que la integran. En concreto mediante el análisis de la presencia y cargos que ocupan varones y mujeres en cada uno de los órganos que integran el Congreso de los Diputados.

Ello constituiría el punto de partida a partir del cual, y mediante Análisis de Contenido, se analizaría tanto la intensidad o rendimiento parlamentario como la agenda del Parlamento, en concreto, los temas que son abordados en las discusiones del Pleno, y más en concreto, en las Comisiones del Congreso.

Como es sabido, las Cortes Generales Españolas constituyen un complejo orgánico compuesto por dos órganos, Congreso de los Diputados y Senado, que a su vez se componen de diversos órganos cada uno de los cuales asume competencias y funciones de muy diversa índole. Los órganos básicos para cada una de las Cámaras serían los siguientes: La Presidencia, la Mesa, la Junta de Portavoces, la Diputación Permanente y las Comisiones.

La actividad parlamentaria se realiza anualmente en dos períodos de sesiones, el primero de septiembre a diciembre y el segundo de febrero a junio, y se reparte entre sesiones plenarias y trabajo en Comisiones. Estas últimas son subdivisiones de la Cámara que desempeñan un papel relevante dentro de las actividades parlamentarias. De hecho, las Comisiones han asumido capacidad decisoria plena para determinados supuestos, hasta el punto de convertirse en el «verdadero alma del trabajo parlamentario».

En el Congreso de los Diputados, las Comisiones pueden ser de carácter permanente o no permanente. Las primeras están previstas con carácter necesario en el Reglamento de las Cámaras y son creadas para toda la legislatura. Las segundas se crean para un trabajo concreto, extinguiéndose una vez finalizado el mismo y, en todo caso, al concluir la legislatura. Las Comisiones Permanentes pueden ser a su vez legislativas o no legislativas según la índole de sus funciones. Las Comisiones Permanentes Legislativas tienen como función estudiar y dictaminar los proyectos y proposiciones de ley y suplir al Pleno en la decisión final del texto cuando exista delegación de competencia legislativa plena (artículos 75 y $76 \mathrm{CE}$ ). De este modo, podría decirse que estas Comisiones denotan una mayor importancia que el resto puesto que se las faculta para tener competencia legislativa plena ${ }^{2}$.

2 No obstante, dicha competencia queda articulada a través de la delegación, de manera que el Pleno no cede a las Comisiones dicha facultad, sino que tal delegación es revocable en cualquier momento. Por otra parte no son delegables para su aprobación por Comisión la reforma constitucional, las cuestiones internacionales, las leyes orgánicas y de bases y los Presupuestos Generales del Estado (art. 75.3 CE). 
Las Comisiones Permanentes no Legislativas tienen funciones no relacionadas con la producción legislativa.

Las Comisiones no Permanentes se crean para un trabajo concreto, extinguiéndose con la finalización de la tarea encomendada y, en todo caso al concluir el período legislativo. Además existen las Comisiones Mixtas Congreso de los Diputados-Senado, como las establecidas para las Relaciones con el Tribunal de Cuentas, con el Defensor del Pueblo, para la Unión Europea o de los Derechos de la Mujer ${ }^{3}$.

De lo visto hasta ahora puede concluirse que aparece claramente regulado en el Reglamento de cada una de las Cámaras el tipo de Comisiones que se pueden constituir en cada legislatura y las competencias que tienen atribuidas cada una de ellas. Así mismo también se regula la composición numérica de las Comisiones. Su composición es el resultado de la pretensión de reflejar la proporcionalidad de las fuerzas existentes entre los grupos parlamentarios. En un principio se parte de la pertenencia de cada parlamentario al menos a una Comisión de la Cámara, si bien puede asistir, con voz pero sin voto a las sesiones de las Comisiones a las que no pertenezca. De esta manera, las Comisiones vienen a reflejar a pequeña escala la composición política de las Cámaras, puesto que están compuestas por diputados o senadores, en su caso, en número proporcional a la fuerza que cada grupo parlamentario tiene en la Cámara correspondiente (Pitkin, 1985).

Ahora bien, la ley no regula cuál ha de ser la composición por género de los distintos órganos que componen nuestras Cámaras legislativas, y, más en concreto de las Comisiones; por lo que la presencia distintiva de varones y mujeres en los órganos del Congreso de los Diputados respondería no tanto al cumplimiento de una normativa jurídica cuanto a decisiones de actores.

Por lo que se refiere al Congreso de los Diputados, se constata que la presencia masculina es muy superior a la femenina en aquellas Comisiones en las que el trabajo en las mismas se centra en lo que hemos denominado ámbitos productivos, y que respondería a un razonamiento moral basado en la ética de la justicia. La composición por géneros es mayoritariamente masculina en las Comisiones de Defensa o de Presupuestos, ambas Comisiones Permanentes Legislativas. Así mismo se da una situación de total ausencia de mujeres en la subcomisión para el seguimiento de los procesos de privatización y reconversión de las empresas pertenecientes al sector público. Además, es mayoritariamente masculina la composición de Comisiones Permanentes no Legislativas como la Comisión del Estatuto de los Diputados y la Comisión de Peticiones. En cambio, aquellas Comisiones en las que la agenda política se centraría fundamentalmente en temas relativos a la atención y cuidado de los demás, y que responderían a lo que hemos denominado ética del cuidado están compuestas mayoritariamente por mujeres. Es el caso de la Comisión Mixta de los Derechos de la Mujer o la Comisión de Política Social y Empleo. La Comisión Mixta para el Estudio del Problema de las drogas contaría con el mismo número de varones que de mujeres.

\footnotetext{
${ }^{3}$ Para un estudio en profundidad de la tipología de Comisiones que integran las Cámaras Legislativas así como las funciones de las mismas, se remite al Reglamento del Congreso de los Diputados y del Senado, respectivamente.
} 
TABLA 1

Estructura orgánica del Congreso de los Diputados según género (VII Legislatura)

\begin{tabular}{|c|c|c|c|c|c|}
\hline & & Varones & Mujeres & Total & $\begin{array}{l}\text { Diferencia } \\
\text { (V-M) }(\%)\end{array}$ \\
\hline \multicolumn{2}{|c|}{ Total miembros en la Cámara } & $\begin{array}{l}71,1 \% \\
(249) \\
\end{array}$ & $\begin{array}{c}28,9 \% \\
(101)\end{array}$ & $\begin{array}{l}100 \% \\
(350)\end{array}$ & $\begin{array}{c}42,2 \% \\
(148)\end{array}$ \\
\hline \multirow{12}{*}{$\begin{array}{l}\text { Ámbitos } \\
\text { productivos }\end{array}$} & Mesa & $44,4 \%(4)$ & $55,6 \%(5)$ & $100 \%(9)$ & $-11,2$ \\
\hline & Junta portavoces & $85,7 \%(18)$ & $14,3 \%(3)$ & $100 \%(21)$ & 71,4 \\
\hline & Diputación Permanente & $77,8 \%(77)$ & $22,2 \%(22)$ & $100 \%(99)$ & 55,6 \\
\hline & Comis. Constitucional & $76,1 \%(35)$ & $23,9 \%(11)$ & $100 \%(46)$ & 52,2 \\
\hline & Comis. Asuntos Exteriores & $77,3 \%(34)$ & $22,7 \%(10)$ & $100 \%(44)$ & 54,6 \\
\hline & Comis. Justicia e Interior & $58,5 \%(31)$ & $41,5 \%(22)$ & $100 \%(53)$ & 17 \\
\hline & Comis. Defensa & $86,0 \%(37)$ & $14,0 \%(6)$ & $100 \%(43)$ & 72 \\
\hline & Comis. Economía y Hacienda & $79,6 \%(43)$ & $20,4 \%(11)$ & $100 \%(53)$ & 59,2 \\
\hline & Subcomis. Estatuto microempresa & & & & \\
\hline & Trabajador autónomo y emprendedor & $83,3 \%(10)$ & $16,7 \%(2)$ & $100 \%(12)$ & 66,6 \\
\hline & Subcomis. Seguimiento privatización & & & & \\
\hline & Reconversión empresas sector público & $100 \%(12)$ & $0 \%(0)$ & $100 \%(12)$ & 100 \\
\hline «Ética de la & Comis. Presupuestos & $92,9 \%(39)$ & $7,1 \%(3)$ & $100 \%(42)$ & 85,8 \\
\hline \multirow[t]{15}{*}{ Justicia» } & Comis. Agricultura, ganadería y pesca & $79,6 \%(39)$ & $20,4 \%(10)$ & $100 \%(49)$ & 59,2 \\
\hline & Comis. Infraestructura & $71,4 \%(45)$ & $28,6 \%(18)$ & $100 \%(63)$ & 42,8 \\
\hline & Comis. Sanidad y Consumo & $58,7 \%(27)$ & $41,3 \%(19)$ & $100 \%(46)$ & 17,4 \\
\hline & Comis.Régim. Administrac. Públicas & $69,0 \%(29)$ & $31,0 \%(13)$ & $100 \%(42)$ & 38 \\
\hline & Comis. Medio Ambiente & $67,3 \%(33)$ & $32,7 \%(16)$ & $100 \%(49)$ & 34,6 \\
\hline & Comis. Ciencia y Tecnología & $70,0 \%(35)$ & $30,0 \%(15)$ & $100 \%(50)$ & 40 \\
\hline & Comis. Reglamento & $73,5 \%(36)$ & $26,5 \%(13)$ & $100 \%(49)$ & 47 \\
\hline & Comis. Estatuto Diputados & $85,7 \%(6)$ & $14,3 \%(1)$ & $100 \%(7)$ & 71,4 \\
\hline & Comis. Peticiones & $87,5 \%(7)$ & $12,5 \%(1)$ & $100 \%(8)$ & 75 \\
\hline & Comis. Control Parlamentario RTVE & $74,4 \%(32)$ & $25,6 \%(11)$ & $100 \%(43)$ & 48,8 \\
\hline & Comis. no permanente valoración & $66,7 \%(18)$ & $33,3 \%(9)$ & $100 \%(27)$ & 33,4 \\
\hline & $\begin{array}{l}\text { Comis. No permanente Conmemoración } \\
\text { transición, exilio y guerra civil }\end{array}$ & $90 \%(9)$ & $10 \%(1)$ & $100 \%(10)$ & 80 \\
\hline & $\begin{array}{l}\text { Comis. Mixta relaciones Tribunal } \\
\text { Cuentas }^{5}\end{array}$ & $80,8 \%(21)$ & $19,2 \%(5)$ & $100 \%(26)$ & 61,6 \\
\hline & Comis. Consultiva de Nombramientos & $75,0 \%(6)$ & $25,0 \%(2)$ & $100 \%(8)$ & 50 \\
\hline & Comis. Mixta la Unión Europea & $81,3 \%(26)$ & $18,7 \%(6)$ & $100 \%(32)$ & 62,5 \\
\hline
\end{tabular}

4 Varón (porcentaje sobre el total de miembros en órgano de la Cámara) - Mujer (porcentaje sobre el total de miembros en órgano de la Cámara). Una diferencia porcentual positiva indica que los varones presentan una mayor tasa de presencia en el órgano correspondiente de la Cámara que las mujeres. Si la diferencia porcentual es negativa, entonces el nivel de presencia femenina será mayor. (En negrilla).

5 Las Comisiones Mixtas están integradas por Diputados y Senadores, los porcentajes han sido calculados sobre el total de los miembros que en dichas Comisiones son diputados para el caso del Congreso, o senadores en el caso de la Cámara Alta. 
TABLA 1

(Continuación)

\begin{tabular}{llrrrr}
\hline Ámbitos & Comis. Educación, Cultura y Deporte & $55,4 \%(31)$ & $44,6 \%(25)$ & $100 \%(56)$ & 10,8 \\
reproductivos & Comis. Política Social y Empleo & $40,4 \%(19)$ & $59,6 \%(28)$ & $100 \%(47)$ & $-19,2$ \\
& Comis. Cooperación Internacional & & & & \\
«Ética del & desarrollo & $67,4 \%(31)$ & $32,6 \%(15)$ & $100 \%(46)$ & 34,8 \\
cuidado» & Comis. Mixta Relaciones Defensor & & & & \\
& Pueblo & $65,4 \%(17)$ & $34,6 \%(9)$ & $100 \%(26)$ & 30,8 \\
& Comis. Mixta derechos de la Mujer & $9,1 \%(3)$ & $90,9 \%(30)$ & $100 \%(33)$ & $-81,8$ \\
& Comis. Mixta estudio problema drogas & $50 \%(13)$ & $50 \%(13)$ & $100 \%(6)$ & 0 \\
\hline
\end{tabular}

Fuente: Elaboración propia a partir de explotación de datos secundarios facilitados por el Congreso de los Diputados para la presente legislatura.

En síntesis, puede decirse que el Congreso de los Diputados constituido tras las Elecciones Generales celebradas en marzo de 2000, presenta una clara división del trabajo político según el género de sus miembros. En general puede decirse que los varones están presentes en mayor medida que las mujeres en aquellas Comisiones en las que el trabajo a desarrollar dentro de las mismas se centraría en temas económicos y laborales, presupuestarios, de defensa etc. Además, coincide que son Comisiones Permanentes, $y$, más en concreto, Comisiones Permanentes Legislativas; y, como se dijo más arriba, destacan por su mayor durabilidad y competencias ya que cuentan con potestad legislativa plena. Por el contrario las mujeres están presentes en mayor medida que los varones, en términos comparativos, en aquellas Comisiones que se caracterizan por su mayor temporalidad y porque el trabajo desarrollado en las mismas se centraría en temas sociales y de atención y cuidado de los demás. Es el caso de algunas Comisiones Especiales y Comisiones Mixtas Congreso-Senado, en especial la Comisión Mixta de los derechos de la Mujer.

Conocida así la diferente presencia de varones y mujeres en las Comisiones del Congreso de los Diputados, procede preguntarse a continuación cuáles son los cargos que ocupan dentro de las mismas.

Como puede apreciarse en la tabla 2 y para el caso concreto de la Cámara Baja, todos los cargos que pueden ocuparse en las distintas Comisiones son desempeñados en mayor medida por varones que por mujeres. No obstante se aprecian diferencias significativas en atención al tipo de cargo de que se trate. Se observan diferencias según género favorables a los varones, muy amplias en los cargos de Portavoz, Secretario y Secretario Primero, Presidente, Vicepresidente y Vicepresidente Primero (más de 50 puntos porcentuales en cada uno de los cargos mencionados) y reducidas en cuanto a los cargos de Portavoz Adjunto, Adscrito y Secretario Segundo, Tercero y Cuarto (15,8 15 y 8 puntos porcentuales respectivamente).

El gráfico 1 recoge las diferencias porcentuales entre varones y mujeres según los cargos que ocupan en las Comisiones del Congreso, poniéndolos en relación con las diferencias porcentuales entre hombres y mujeres para el total de la Cámara en su conjunto ( 42,4 puntos porcentuales a favor de los varones). De esta manera, se observa que existe una sobrerrepresentación masculina en los cargos de Portavoz, Secretario y Secretario Primero, Presidente, Vicepresidente y Vice- 
presidente Primero. Por el contrario, las mujeres estarían sobrerrepresentadas en los cargos de Vicepresidente Segundo Tercero y Cuarto, Portavoz Adjunto y Secretario Segundo Tercero y Cuarto. Las diferencias en puntos porcentuales entre varones y mujeres en lo que se refiere a las vocalías viene a ser proporcional a las diferencias porcentuales en torno a la presencia por género para la Cámara en su conjunto (40,2 y 42,4 puntos porcentuales respectivamente).

\section{TABLA 2 \\ Cargos ocupados en las Comisiones del Congreso de los Diputados según género (VII Legislatura)}

\begin{tabular}{lrrrc}
\hline $\begin{array}{l}\text { Cargos ocupados en las Comisiones del } \\
\text { Congreso de los Diputados }\end{array}$ & Varones & Mujeres & Total & $\begin{array}{c}\text { Diferencia (Puntos } \\
\text { porcentuales) }\end{array}$ \\
\hline Presidente & $76,7 \%(20)$ & $23,0 \%(6)$ & $100 \%(26)$ & 53,7 \\
Vicepresidente y Vicepresidente Primero & $75,0 \%(18)$ & $25,0 \%(6)$ & $100 \%(24)$ & 50 \\
Vicepresidente Segundo, Tercero y Cuarto & $60,1 \%(14)$ & $39,1 \%(9)$ & $100 \%(23)$ & 21 \\
Secretario y Secretario Primero & $77,3 \%(17)$ & $22,7 \%(5)$ & $100 \%(22)$ & 54,6 \\
Secretario Segundo, Tercero y Cuarto & $54,2 \%(13)$ & $45,9 \%(11)$ & $100 \%(24)$ & 8,3 \\
Portavoz & $78,8 \%(123)$ & $21,2 \%(33)$ & $100 \%(156)$ & 57,6 \\
Portavoz Adjunto & $57,9 \%(22)$ & $42,1 \%(16)$ & $100 \%(38)$ & 15,8 \\
Vocal & $70,1 \%(407)$ & $29,9 \%(174)$ & $100 \%(581)$ & 40,2 \\
Adscrito & $57,5 \%(88)$ & $42,5 \%(65)$ & $100 \%(153)$ & 15 \\
Presencia en el conjunto de la Cámara & $\mathbf{7 1 , 2 ( 2 4 9 )}$ & $\mathbf{2 8 , 8 \% ( 1 0 1 )}$ & $\mathbf{1 0 0 \% ( 3 5 0 )}$ & $\mathbf{4 2 , 4}$ \\
\hline
\end{tabular}

Fuente: Elaboración propia.

Nota: Los cargas de Vicepresidente Tercero y Vicepresidente Cuarto tan sólo existen en una Comisión, en concreto, la Comisión de Reglamento por lo que han sido tratados junto con el cargo de Vicepresidente Segundo. En dicha Comisión, el cargo de vicepresidente tercero lo ocupa una mujer. Vicepresidente cuarto un varón. Lo mismo sucede en el caso de los Cargos Secretario Tercero y Secretario Cuarto. Tan sólo existen en la Comisión de Reglamento, y han sido tratados junto con el cargo de Secretario Segundo. En dicha Comisión, los cargos de Secretario Tercero y Secretario Cuarto son ocupados ambos por mujeres.

El cargo de Secretario tan sólo existe en dos Comisiones, en concreto, la Comisión del Estatuto de los Diputados y la Comisión de Peticiones con lo que ha sido tratado junto con el cargo de Secretario Primero. En ambas Comisiones, el cargo de secretario lo ocupan varones.

En síntesis, puede decirse que en el Congreso de los Diputados las mujeres experimentan una doble discriminación, a saber, discriminación por cargos, puesto que aquellos puestos que darían cuenta de un mayor prestigio, visibilidad y, podría decirse, reconocimiento social, están comparativamente ocupados en mayor medida por varones. $Y$ por otro lado, discriminación por sector, pues las mujeres están presentes en mayor medida en aquellas Comisiones que, como se dijo más arriba, se caracterizarían por su temporalidad y porque las actividades propias del trabajo parlamentario a desarrollar dentro de las mismas estarían relacionadas con lo que hemos denominado el ámbito de la reproducción y que responderían a un razonamiento moral basado en lo que se ha definido como la ética del cuidado. De tal manera que, salvo excepciones, podría decirse que la probabilidad de presencia femenina en puestos de alta «visibilidad política» se reduce a medida que las Comisiones del Congreso ganan en durabilidad y permanencia a lo largo de la legislatura, competencias y el trabajo a desarrollar dentro de las mismas responde al razonamiento moral que hemos denominado ética de la justicia y que hemos clasificado dentro del ámbito de la producción. 


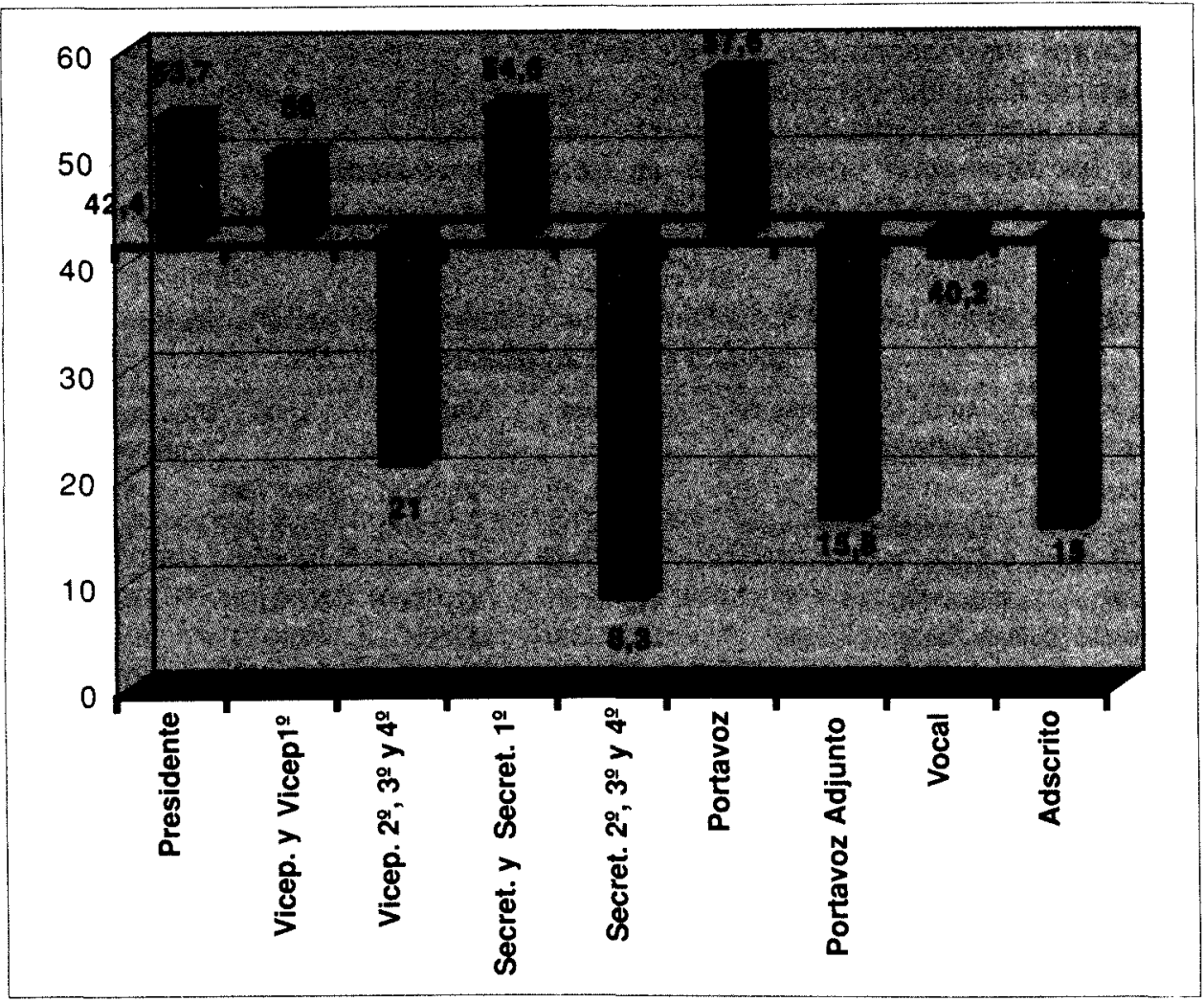

GráfICO 1. Género y cargos ocupados en los órganos del Congreso

(Diferencias porcentuales entre varones y mujeres)

La figura 2 recoge de manera resumida la propuesta de Dalherup aplicada al Congreso de los Diputados de la VII Legislatura, en concreto, a las Comisiones que integran la Cámara Baja. En este gráfico figuran representadas algunas de las Comisiones más significativas del Congreso según su composición por género y el desarrollo de una agenda y estilo específico según género.

Siguiendo la propuesta de Dalherup, podría suceder que en aquellas Comisiones que se caracterizaran por ser «grupos homogéneos» o "grupos sesgados», esto es, por la presencia mayoritaria de un grupo (varones en el caso de la Comisión de Presupuestos, mujeres en el caso de la Comisión Mixta de los Derechos de la Mujer), los grupos minoritarios (mujeres en el primer caso, varones en el segundo) desarrollasen estilos políticos y agendas de carácter adaptativo a la de los grupos mayoritarios; Sin embargo, cuando se diera cierta situación de equilibro entre subgrupos, como sucede, por ejemplo, en la Comisión de Educación, Cultura y Deporte, o incluso, en el caso de la Comisión Mixta para el Estudio del Problema de las Drogas, podría esperarse que los grupos que tradicionalmente eran minoritarios, se distanciasen de los mayoritarios en su quehacer político, tanto en su estilo de liderazgo como en su agenda. 


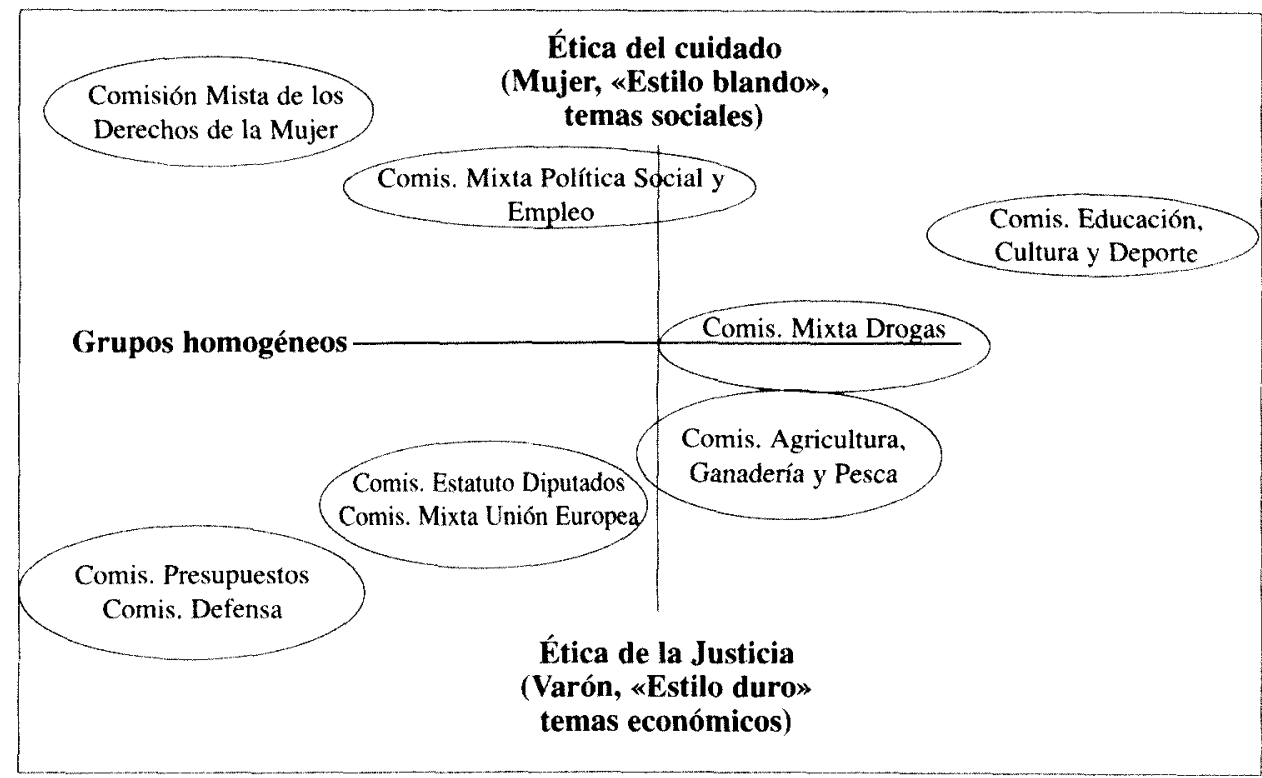

Figura 2. Tipos de Comisiones del Congreso de los Diputados: Composición según género y estilo político.

\subsection{EL TRABAJO POLÍTICO DESARROLLADO EN LAS COMISIONES: RENDIMIENTO PARLAMENTARIO Y ORDEN DEL DÍA DE LAS SESIONES}

Como ya se indicó más arriba, la actividad parlamentaria se realiza anualmente en dos períodos de sesiones, el primero de septiembre a diciembre, y el segundo de febrero a junio, y se reparte en sesiones plenarias y trabajo en Comisiones.

La actividad política de cada una de las Comisiones en la VII Legislatura se inició en los primeros días de Mayo de 2000 tras la celebración de las últimas Elecciones Generales, habiéndose celebrado a finales de Junio de 2001 un total de 335 sesiones. El número de sesiones celebradas cada año según el tipo de Comisión se recogen de manera detallada en la tabla 3.

El análisis del orden del día de las sesiones celebradas por cada una de las Comisiones permitirá conocer, en buena medida, la actividad política y las normas de procedimiento que han de seguirse en función del tipo de actividad parlamentaria que se trate.

En este sentido y de manera muy general puede decirse que para cada una de las Comisiones la primera sesión tiene como orden del día la Constitución de la Comisión de que se trate, así como las votaciones para la elección dentro de cada Comisión de la Mesa de la Comisión, donde se elige al presidente de la Comisión, dos vicepresidentes y dos secretarios, según lo establecido en el artículo 41 del Reglamento del Congreso de los Diputados (RCD). 
TABLA 3

Sesiones celebradas en las Comisiones del Congreso de los Diputados según tipo de Comisión y período legislativo (VII Legislatura)

\begin{tabular}{|c|c|c|c|c|}
\hline \multicolumn{5}{|c|}{ VII LEGISLATURA } \\
\hline \multirow{2}{*}{ Tipo de Comisiones } & \multirow{2}{*}{ Comisiones } & \multicolumn{3}{|c|}{ Sesiones } \\
\hline & & Año 2000 & Año 2001 & Total \\
\hline & Constitucional & 6 & 3 & 9 \\
\hline & Asuntos Exteriores & 11 & 5 & 16 \\
\hline & Justicia e Interior & 15 & 16 & 31 \\
\hline & Defensa & 8 & 5 & 13 \\
\hline & Educación, Cultura y Deporte & 8 & 10 & 18 \\
\hline Comisiones & Economía y Hacienda & 11 & 14 & 25 \\
\hline Permanentes & Presupuestos & 7 & 3 & 10 \\
\hline \multirow[t]{7}{*}{ Legislativas } & Agricultura, Ganadería y Pesca & 9 & 10 & 19 \\
\hline & Infraestructuras & 9 & 12 & 21 \\
\hline & Política Social y Empleo & 5 & 7 & 12 \\
\hline & Sanidad y Consumo & 7 & 7 & 14 \\
\hline & Régim. Administraciones Públicas & 5 & 6 & 11 \\
\hline & Medio Ambiente & 7 & 11 & 18 \\
\hline & Ciencia y Tecnología & 7 & 9 & 16 \\
\hline & Reglamento & 1 & 1 & 2 \\
\hline Comisiones & Estatuto de los Diputados & 1 & 1 & 2 \\
\hline Permanentes & Peticiones & 1 & 1 & 2 \\
\hline \multirow[t]{2}{*}{ no legislativas } & Control Parlamentario de RTVE & 7 & 5 & 12 \\
\hline & Cooperac. Internac. para desarrollo & 5 & 6 & 11 \\
\hline \multicolumn{5}{|c|}{ Comisiones de Estudio Comisión no Perman. Valoración } \\
\hline \multirow{6}{*}{$\begin{array}{l}\text { Comisiones Mixtas } \\
\text { Permanentes }\end{array}$} & & & 13 & \\
\hline & $\begin{array}{l}\text { Comisión Mixta para las Relaciones } \\
\text { con el Tribunal de Cuentas }\end{array}$ & 6 & 6 & 12 \\
\hline & Comisión Mixta para la Unión Europea & 5 & 8 & 13 \\
\hline & $\begin{array}{l}\text { Comisión Mixta de Relaciones con } \\
\text { el Defensor del Pueblo }\end{array}$ & 4 & 2 & 6 \\
\hline & Comisión Mixta Derechos de la Mujer & 3 & 4 & 7 \\
\hline & Comision Mixta Problema de las Drogas & 6 & 6 & 12 \\
\hline \multicolumn{2}{|c|}{ Comisión Consultiva de Nombramientos } & 2 & - & 2 \\
\hline \multicolumn{2}{|l|}{ TOTAL SESIONES } & 164 & 171 & 335 \\
\hline
\end{tabular}

Fuente: Elaboración propia a partir del Diario de Sesiones del Congreso de los Diputados de la VII Legislatura (Comisiones).

En la segunda sesión de cada una de las Comisiones, el orden del día suele estar integrado por diversos aspectos, constituyendo, por lo general, el punto central del mismo, la comparecencia del Ministro correspondiente quien a petición propia o por solicitud de un determinado grupo parlamentario, comparece ante la 
Comisión para informar de las líneas generales de la política de su departamento, así como de las prioridades y políticas que piensa impulsar en relación a las materias vinculadas a dicha Comisión durante el período legislativo correspondiente.

Cuando se produce la comparecencia del Ministro o de cualquier otro miembro del gobierno, o bien de distintas personalidades y cargos de la Administración del Estado, para informar sobre temas relacionados con el objeto de la Comisión, el orden formal de celebración de este tipo de comparecencias es el siguiente: En primer lugar interviene el compareciente, posteriormente intervienen los grupos parlamentarios en función de su inversa representatividad en la Cámara, concluyendo con la intervención del grupo parlamentario que apoya al Gobierno. En estas intervenciones los grupos parlamentarios formularán preguntas, aclaraciones o solicitud de ampliación de información. Posteriormente los comparecientes contestan a las preguntas que les hayan sido formuladas, y en el caso de que fuera necesario, se abriría un segundo turno de intervenciones (artículos 202 y $203 \mathrm{RCD}$ ).

El orden del día de una Sesión puede incluir, asimismo, el debate y votación de proposiciones no de ley; la emisión de dictámenes a la vista de informes elaborados por las ponencias correspondientes sobre determinados proyectos de ley, la formulación de preguntas al Gobierno, así como solicitudes de creación de subcomisiones y ponencias para el estudio de un asunto de relevancia política, interpelaciones al Gobierno y a cada uno de sus miembros, o la aprobación de proyectos de ley por parte de aquellas Comisiones que cuentan con competencia legislativa plena ${ }^{6}$.

\section{DISEÑO DE LA INVESTIGACIÓN}

El análisis realizado hasta ahora ha permitido conocer de manera detallada la presencia y cargos que varones y mujeres ocupan en los distintos órganos que integran el Congreso de los Diputados, de donde se ha podido constatar la existencia en la Cámara Baja de una clara división del trabajo político según género. Asimismo, ciertos rasgos procedimentales regulados en el Reglamento del Congreso y en la Constitución Española delimitan, en buena medida, el modo de actuación de la clase política, pues establecen ciertas reglas procedimentales a seguir (duración de la intervención, orden de intervención de los partidos políticos y actores comparecientes etc.) en función de la actividad parlamentaria de que se trate. Ahora bien, cabe analizar el ejercicio efectivo del trabajo político desarrollado en el Congreso mediante Análisis de Contenido del Diario de Sesiones. En este sentido en las páginas que siguen se presenta una propuesta metodológica que permitiría conocer si existe un estilo y una agenda política de género en el Parlamento Español mediante Análisis de Contenido del Diario de

${ }^{6}$ Para un análisis detallado del procedimiento legislativo en el Congreso así como del papel y funciones que en el mismo cumplen las Comisiones se remite a Bustos, R. (2000): «La función legislativa», en Martínez, A (Edit): El Congreso de los Diputados en España: funciones y rendimiento, Madrid, Tecnos, pp. 37-68. 
Sesiones de las Comisiones que integran el Congreso de los Diputados, analizando de manera específica los temas que son abordados en las discusiones de las Comisiones y la manera en que son tratados, en atención al tipo de Comisiones y Sesiones celebradas en el período legislativo actual así como según la composición por género de las mismas, siguiendo la propuesta de Dalherup comentada anteriormente (ver figura 2).

El diseño metodológico consistiría, por tanto, en la explotación de los Diarios de Sesiones de las Comisiones que integran la Cámara Baja en la VII Legislatura. Para ello se propone realizar análisis de contenido de corte estadístico. Esto es, el diseño de una ficha de codificación que, a la vista de los datos analizados hasta ahora, permitiese recoger información relevante en atención a los objetivos mencionados. Los ítems que se proponen para su inclusión en la ficha de codificación diseñada para medir la agenda y el estilo político de la clase parlamentaria española son los que figuran a continuación.

En primer lugar, se incluiría un ítem que permitiría conocer cuál es la fuente de información que se va a manejar, puesto que el Congreso de los Diputados cuenta con Diario de Sesiones tanto del Pleno y Diputación Permanente como de las Comisiones o las Comisiones Mixtas.

El segundo ítem supone la delimitación operativa del marco temporal al que se refiere el fenómeno objeto de estudio.

Delimitada la fuente de información y el período de tiempo, los ítems tercero y cuarto dan cuenta de la Comisión que concretamente va a ser objeto de análisis así como el tipo de Comisión de que se trata según la tipología de Comisiones que existen actualmente en el Congreso de los Diputados.

Tras definir la Comisión objeto de estudio, se incluirían una serie de ítems que permitirían una rápida identificación de la Sesión que se va a analizar. En concreto serían los siguientes: Tipo de Sesión Plenaria, número de sesión, fecha de celebración de la Sesión, incluyendo día, mes y año, así como su duración.

Para una visión de conjunto del contenido de la Sesión se añadiría un ítem que daría cuenta del Orden del Día de la Sesión objeto de análisis.

A continuación y por cada compareciente se recogerían una serie de ítems, cada uno de los cuales centrados en distintos aspectos. En primer lugar, ítems que permitirían conocer ciertos rasgos de identificación del ponente: género del interviniente, partido político de pertenencia y cargo que ocupa en la Comisión de la que forma parte. En segundo lugar un ítem que daría cuenta de la duración de la intervención; para finalizar con un conjunto de ítems que darían cuenta de la agenda y del estilo político desarrollado por la clase parlamentaria española. En concreto serían los siguientes: temática básica que es abordada en la intervención, resultado de la propuesta (aprobada o no), tono y estilo del compareciente.

A continuación y a modo de ejemplo se realizará un estudio exploratorio de los temas abordados en las discusiones de las Comisiones a través de Análisis de Contenido de las Sesiones de las Comisiones que integran el Congreso de los Diputados. Para la selección de una muestra de las 335 Sesiones celebradas entre el inicio de la actual legislatura y Junio de 2001, de un total de 26 Comisiones se ha atendido a la propuesta teórica de Dalherup comentada más arriba donde ponía de manifiesto la asociación entre presencia de la mujer en las sedes parla- 
mentarias y la génesis y desarrollo de una agenda y un estilo político según género (ver figura 2).

\section{Protocolo de análisis del Diario de Sesiones del Congreso de los Diputados}

P1. Diario de Sesiones del Congreso de los Diputados

\begin{tabular}{|c|c|}
\hline Pleno y Diputación Permanent & (2.............................. \\
\hline Comisiones & …........................ 2 \\
\hline Comisiones Mixtas & …….................... 3 \\
\hline
\end{tabular}

P2. Legislatura

\begin{tabular}{|c|c|}
\hline Constituyente (1977-1979) & 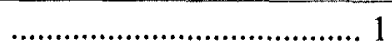 \\
\hline I Legislatura (1979-1982) & (2) \\
\hline II Legislatura (1982-1986) & 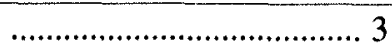 \\
\hline III Legislatura (1986-1989) & 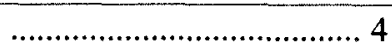 \\
\hline IV Legislatura (1989-1992) & 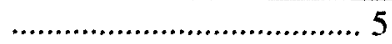 \\
\hline V Legislatura (1992-1996) & 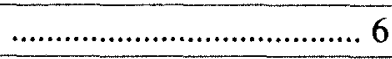 \\
\hline VI Legislatura (1996-2000) & ..................... 7 \\
\hline VII Legislatura $(2000-\ldots . .)$. & 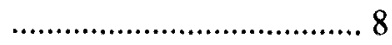 \\
\hline
\end{tabular}

P3. Tipo de Comisión

\begin{tabular}{|l|l|}
\hline Comisiones Permanentes Legislativas & $\ldots \ldots \ldots \ldots \ldots \ldots . .1$ \\
\hline Comisiones Permanentes no Legislativas & $\ldots \ldots \ldots \ldots \ldots \ldots \ldots . \ldots \ldots$ \\
\hline Comisiones de Estudio & $\ldots \ldots \ldots \ldots \ldots \ldots . .3$ \\
\hline Comisiones Mixtas Permanentes & $\ldots \ldots \ldots \ldots \ldots \ldots . .4$ \\
\hline
\end{tabular}

P4. Comisión

\begin{tabular}{|c|}
\hline Comisión Constitucional ............................................................................... 1 \\
\hline Comisión de Asuntos Exteriores......................................................................... 2 \\
\hline Comisión de Justicia e Interior .......................................................................... 3 \\
\hline 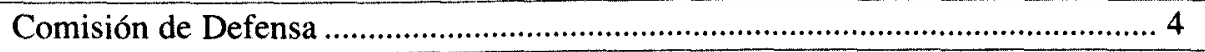 \\
\hline Comisión de Educación, Cultura y Deporte \\
\hline Comisión de Economía y Hacienda ............................................................... 6 \\
\hline 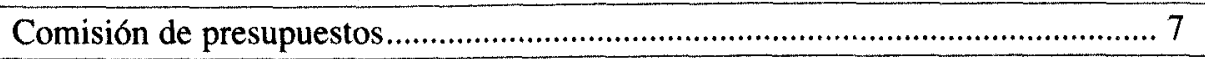 \\
\hline Comisión de agricultura, ganadería y pesca ................................................ 8 \\
\hline 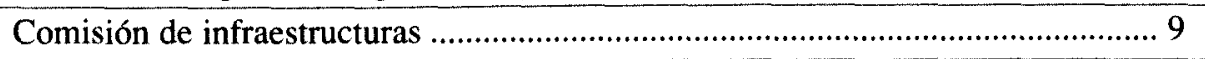 \\
\hline
\end{tabular}




\begin{tabular}{|c|}
\hline Comisión de política social y empleo \\
\hline Comisión de sanidad y consumo \\
\hline Comisión de régimen de las administraciones públicas ........................... 12 \\
\hline Comisión de medio ambiente \\
\hline 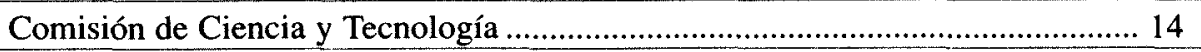 \\
\hline Comisión de Reglamento \\
\hline Comisión del Estatuto de los Diputados \\
\hline Comisión de Peticiones \\
\hline 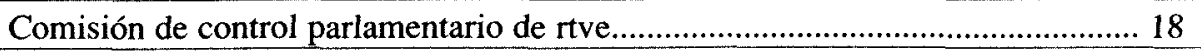 \\
\hline Comisión de Cooperación Internacional para el Desarrollo................................ 19 \\
\hline $\begin{array}{l}\text { Comisión no Permanente valoración resultados aplicación } \\
\text { recomendaciones Pacto de Toledo }\end{array}$ \\
\hline Comisión no Permanente Conmemoración transición, exilio y guerra civil.......... 21 \\
\hline Comisión mixta para las relaciones con el tribunal de cuentas........................... 22 \\
\hline 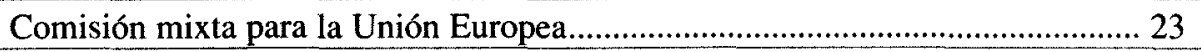 \\
\hline Comisión mixta de relaciones con el defensor del pueblo ........................................24 \\
\hline 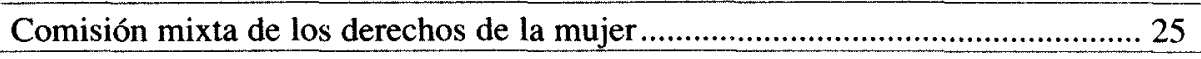 \\
\hline 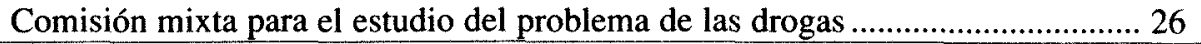 \\
\hline Comisión Consultiva de Nombramientos ........... \\
\hline
\end{tabular}

P5. Tipo de Sesión Plenaria

\begin{tabular}{|c|c|}
\hline Ordinaria & 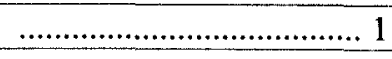 \\
\hline Extraordinaria & 2 \\
\hline
\end{tabular}

P6. Sesión Plenaria Número

P7. Fecha de celebración de la Sesión

Día
Mes -
Año

P8. Hora de inicio de la Sesión

P9. Hora de finalización de la Sesión 
P10. Orden del día de la Sesión

\begin{tabular}{|c|c|}
\hline Constitución de la Comisión & . \\
\hline Comparecencias & . \\
\hline Proposiciones no de Ley & 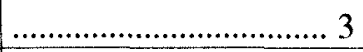 \\
\hline Preguntas & 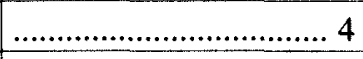 \\
\hline Solicitudes de creación de Subcomisiones y ponencias & $\ldots$ \\
\hline Dictamen sobre & . \\
\hline Otros, ¿Cuál? & $\ldots+\ldots+1$ \\
\hline
\end{tabular}

P11. Género del compareciente

\begin{tabular}{|c|c|}
\hline Varón & 1 \\
\hline Mujer & 2 \\
\hline
\end{tabular}

P12. Partido político al que pertenece el compareciente

\begin{tabular}{|c|c|}
\hline Partido Popular & ㄴ..ㄴ..1 \\
\hline Partido Socialista Obrero Español & $\ldots$ \\
\hline Bloque Nacionalista Galego & $\ldots$ \\
\hline Izquierda Unida & $\ldots+1$ \\
\hline Coalición Canaria & 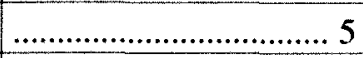 \\
\hline Convergencia i Uniò & 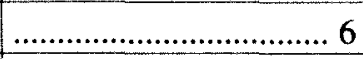 \\
\hline Partido Nacionalista Vasco & $\ldots \ldots+\ldots \ldots+\ldots+\ldots+\ldots-1$ \\
\hline Chunta Aragonesista & 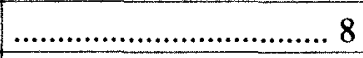 \\
\hline Eusko Alkartasuna & 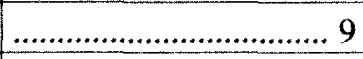 \\
\hline Partido Andalucista & $\ldots+\ldots \ldots+\ldots \ldots+\ldots \ldots+\ldots-10$ \\
\hline Esquerra Republicana de Catalunya & 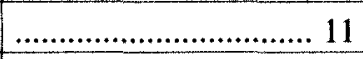 \\
\hline Iniciativa per Catalunya-Verds & 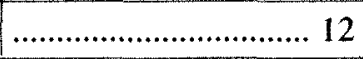 \\
\hline
\end{tabular}

P13. Cargo que ocupa el interviniente en la Comisión de la que forma parte

\begin{tabular}{|c|c|}
\hline Sin cargo en la Comisión & 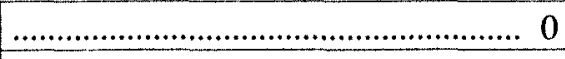 \\
\hline Presidente & (1) \\
\hline Vicepresidente & (n) \\
\hline Vicepresidente $1^{\circ}$ & (1) \\
\hline Vicepresidente $2^{\circ}$ & (1) \\
\hline Vicepresidente $3^{\circ}$ & (1) \\
\hline
\end{tabular}




\begin{tabular}{|c|c|}
\hline Vicepresidente $4^{\circ}$ & (1) \\
\hline Secretario & (1) \\
\hline Secretario $1^{\circ}$ & 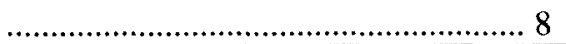 \\
\hline Secretario $2^{\circ}$ & (1) \\
\hline Secretario $3^{\circ}$ & 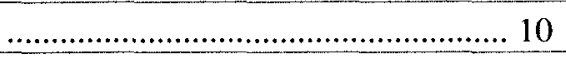 \\
\hline Secretario $4^{\circ}$ & 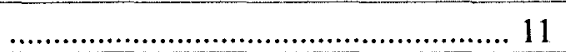 \\
\hline Portavoz & $\ldots$ \\
\hline Portavoz Titular & 1. \\
\hline Portavoz Adjunto & (1) \\
\hline Portavoz Sustituto & (1) \\
\hline Viceportavoz & 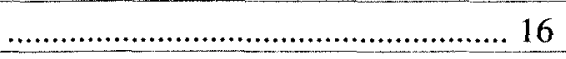 \\
\hline Miembro Titular & (1) 17 \\
\hline Miembro Suplente & 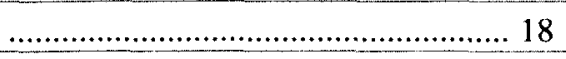 \\
\hline Vocal & . \\
\hline Vocal Suplente & 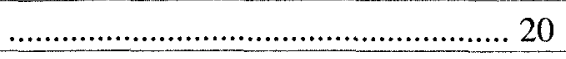 \\
\hline Adscrito & $\ldots$ \\
\hline Letrado & 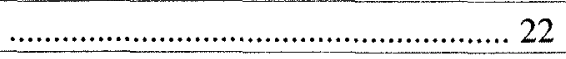 \\
\hline Ponente & 23 \\
\hline
\end{tabular}

P14. Cargo del interviniente de la Comisión sin ser miembro de la misma

Miembro del Gobierno

Funcionario o alto cargo de la administración del Estado Otros, Cuál?

ㄱ..ㄴ..…………… 1

P15. Duración de la intervención

P16. Tema de la intervención

P17. Resultado de la propuesta

\begin{tabular}{|c|c|}
\hline Apobada & (1) \\
\hline No aprobada & 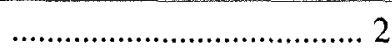 \\
\hline
\end{tabular}


P18. Tono

\begin{tabular}{|c|c|}
\hline Descriptivo & (1) \\
\hline Prescriptivo & (2) \\
\hline Emotivo/testimonial & $\ldots \ldots \ldots \ldots \ldots \ldots . . . . .3$ \\
\hline Otro, ¿cuál? & 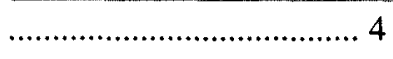 \\
\hline
\end{tabular}

P19. Estilo político

\begin{tabular}{|c|c|}
\hline Crítica & (1) \\
\hline Ataque & ㄴ. \\
\hline Colaboración & ㄴ.1-1. \\
\hline Otros, ¿Cuál? & 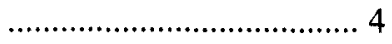 \\
\hline
\end{tabular}

\section{ANÁLISIS EMPÍRICO EXPLORATORIO}

Siguiendo la propuesta de Drude Dalherup que como ya se ha dicho resaltaba la asociación entre la presencia femenina en las sedes parlamentarias y el surgimiento y desarrollo de una agenda y un estilo político propio, se ha procedido a realizar análisis de contenido del Diario de Sesiones de las Comisiones del Congreso de los Diputados, tomando como estudio de caso tres de ellas. Los criterios seguidos para la selección de las mismas así como las sesiones analizadas se recogen de manera detallada en la tabla 4.

\section{TABLA 4}

Composición según género y sesiones celebradas en algunas de las Comisiones del Congreso de los Diputados (VII Legislatura)

\begin{tabular}{|c|c|c|c|c|}
\hline \multicolumn{5}{|c|}{ VII LEGISLATURA } \\
\hline \multirow[t]{2}{*}{ Comisiones } & \multirow[t]{2}{*}{ Sesiones } & \multicolumn{2}{|c|}{$\begin{array}{c}\text { Composición de la } \\
\text { comisión? }\end{array}$} & \multirow[t]{2}{*}{$\begin{array}{l}\text { Tipo de grupo } \\
\text { (Dalherup) }\end{array}$} \\
\hline & & Varón & Mujer & \\
\hline \multirow[t]{2}{*}{$\begin{array}{l}\text { Comisión mixta de } \\
\text { los derechos de } \\
\text { la mujer }\end{array}$} & $\begin{array}{l}\text { N. }{ }^{\circ} \text { : Celebrada el lunes } 18 \text { de } \\
\text { Septiembre de } 2000 \text { en el } \\
\text { Palacio del Senado }\end{array}$ & $5(9,3 \%)$ & $49(90,7 \%)$ & $\begin{array}{c}\text { GRUPOS } \\
\text { HOMOGENEOS } \\
\text { (Totalmente dominados } \\
\text { por un grupo mayoritario) }\end{array}$ \\
\hline & & & & + MUJERES \\
\hline
\end{tabular}

${ }^{7}$ Las Comisiones Mixtas están integradas por Diputados/as y Senadores/as. En esta tabla los porcentajes se han calculado sobre el total de los miembros de la Comisión sin distinguir según la Cámara a la que pertenecen, por lo que se incluyen los miembros de la Comisión que son senadores/as. 
TABLA 4

(Continuación)

\begin{tabular}{clccc}
\hline $\begin{array}{c}\text { Comisión de } \\
\text { educación, cultura } \\
\text { y deporte }\end{array}$ & $\begin{array}{l}\text { No }^{2} \text { 18: Celebrada el miércoles 13 } \\
\text { de Junio de 2001 en el Palacio } \\
\text { del Congreso de los Diputados }\end{array}$ & $31(55,4 \%)$ & $25(44,6 \%)$ & $\begin{array}{c}\text { GRUPOS } \\
\text { EQUILIBRADOS } \\
\text { (relación entre subgrupos } \\
\text { cercana a la mitad) } \\
\text { VARONES +/- } \\
\text { MUJERES }\end{array}$ \\
\hline $\begin{array}{c}\text { Comisión de } \\
\text { infraestructuras }\end{array}$ & $\begin{array}{l}\text { № } 2^{\circ} \text { : Celebrada el martes 12 } \\
\text { de Junio de 2001 en el Palacio } \\
\text { del Congreso de los Diputados }\end{array}$ & $45(71,4 \%)$ & $18(28,6 \%)$ & $\begin{array}{c}\text { GRUPOS } \\
\text { HOMOGÉNEOS } \\
\text { (Totalmente dominados } \\
\text { por un grupo mayoritario) } \\
\text { + VARONES }\end{array}$ \\
\hline
\end{tabular}

Fuente: Elaboración propia a partir del Diario de Sesiones del Congreso de los Diputados (Comisiones).

En aras a la claridad expositiva y aunque pueda resultar algo extenso se realizará el análisis de contenido en función de la Comisión que se esté analizando, reservandosé un último apartado de este trabajo al desarrollo de una visión de conjunto del contenido de todas ellas.

\subsection{Comisión Mixta de los Derechos de la Mujer: ¿agenda y estilo político femenino?}

Para estudiar los temas que propone la clase política española en sus discusiones en las Comisiones así como los modos en que son abordados, se ha seleccionado en el caso concreto de la Comisión Mixta de los Derechos de la Mujer la Sesión N. ${ }^{\circ}$, celebrada el lunes 18 de Septiembre de 2000 en el Palacio del Senado. El Orden del día viene caracterizado por la Comparecencia a petición propia y del Grupo Parlamentario Socialista del Congreso de los Diputados, del Ministro de Trabajo y Asuntos Sociales, excelentísimo Señor don Juan Carlos Aparicio Pérez, para informar sobre la posición de su Ministerio en Políticas de mujer.

Analizar el modo de ejercicio de la política por parte de la clase parlamentaria mediante el estudio del contenido del Diario de Sesiones de las Comisiones del Congreso, no resulta tarea fácil, puesto que por una parte existen una serie de reglas de procedimiento recogidas tanto en la Constitución Española como en el Reglamento de la Cámara que limitan la libertad de actuación de la élite política, pero además existirían unas «normas no escritas» propias del lenguaje político y que darían cuenta de rasgos de cortesía parlamentaria comunes a los miembros del Congreso con cierta independencia del género de los mismos, sin olvidar ciertas actitudes de «satisfacción/optimismo político versus insatisfacción/ pesimismo» de los intervinientes en función del partido político de procedencia.

En atención a las reglas de procedimiento y como ya se comentó en secciones anteriores, el orden de intervenciones y de desarrollo de una sesión en la que comparecen distintas personalidades para informar sobre temas relacionados con el objeto de la Comisión es el siguiente: $\mathrm{El}$ compareciente hace una primera 
exposición, de la forma y con el contenido que tenga por conveniente y oportuno y durante el tiempo que considere necesario, y a continuación por los diferentes grupos parlamentarios, comenzando por el grupo solicitante de la comparencia, y por orden de mayor o menor representación parlamentaria, concluyendo con el grupo que apoya al Gobierno, se le formularán aquellas preguntas, sugerencias o puntualizaciones que crean también oportuno, y por último las contestará también durante el tiempo que considere necesario.

En la Sesión Segunda de la Comisión Mixta de los Derechos de la Mujer comparece el Ministro de Trabajo para dar cuenta de la posición de su Ministerio en políticas de Mujer.

Comienza con un lenguaje de claro agradecimiento y satisfacción al comparecer en la Comisión para informar de lo que el Gobierno piensa llevar a cabo en políticas de mujer y de puesta a disposición de él y todo el Gobierno para informar de las medidas que piense poner en marcha el Ejecutivo en materia de igualdad de oportunidades y dar cuenta de los logros alcanzados, sobre todo, durante la presidencia del Gobierno del Partido Popular, al que él representa.

Pese a que es consciente de lo que falta por hacer en materia de igualdad de oportunidades, y que no hay que «bajar la guardia», emplea un lenguaje optimista e incluso llega a hablar de «optimismo razonable», destacando que «el objetivo de la igualdad se ha materializado en hechos concretos», pasando de «rótulo» a «discurso», y, finalmente a «documento», y lo que es más «documento útil».

Las políticas de igualdad «figuran no solamente en el rótulo del Ministerio de Trabajo y Asuntos Sociales sino que también han tenido una plasmación importante en los discursos de inicio de una legislatura: en el discurso de investidura del propio Presidente del Gobierno, teniendo también plasmación en documentos... (Ministro de Trabajo, Comisión Mixta de los Derechos de la Mujer, Sesión N. 2, pp. 109).

Y en esa clara actitud «optimismo político» llega a calificar uno de los instrumentos diseñados y ejecutados para la consecución de la igualdad, cual es el III Plan de Igualdad de Oportunidades entre hombres y mujeres (1997-2000) como «primera referencia para mantener lo que haya de entenderse como positivo y útil para el conjunto de las mujeres españolas».

Además, no sólo muestra actitud de optimismo político sino que la preocupación por parte del Gobierno en materia de igualdad parece ser seria y rigurosa, pues está presente y participa activamente en foros internacionales sobre políticas de igualdad: Naciones Unidas, Unión Europea, y convoca a otros actores políticos autonómicos y locales, así como actores más cercanos a los intereses y necesidades de las mujeres -asociaciones de mujeres- para que trabajen y sigan trabajando «a favor de las mujeres». Asimismo, emplea de continuo la idea del "consenso hásico» entre las distintas fuerzas políticas en cuanto al objetivo final de "avance en la consecución de la igualdad efectiva» así como su plena disposición para el diálogo, pues «trataremos de escuchar al resto de las administraciones y a las asociaciones que desde hace tiempo vienen trabajando mucho y bien a favor de esta igualdad». 
Déficit democrático, injusticia social y despilfarro son los adjetivos que utiliza para calificar el hecho de que las mujeres por razón de su género encuentren mayores dificultades para acceder a un puesto de trabajo. A pesar de que reconoce la inferior situación de la mujer en ciertas esferas del mundo laboral: tasa de actividad, formación etc, destaca siempre los logros alcanzados durante la pasada legislatura. Y aporta siempre cifras, que, en sus palabras, llevan a pensar en un «horizonte de igualdad»:

«Durante la pasada legislatura la tasa de actividad femenina se ha incrementado en casi tres puntos y la masculina lo ha hecho en poco más de medio punto...».

«El número de mujeres ocupadas asciende en la actualidad, según la encuesta de la Población Activa del segundo trimestre de 2000 a 5.389.800 mujeres, gracias al fuerte incremento experimentado durante estos últimos cuatro años......».

«La tasa de ocupación femenina ha aumentado en seis puntos y medio en los últimos cinco años...»

«Desde el inicio de la pasada legislatura se han suscrito 1.562 .245 contratos estables a mujeres, lo que ha significado una subida de cinco punto porcentuales....» (Ministro de Trabajo, Comisión Mixta de los Derechos de la Mujer, Sesión N. ${ }^{\circ}$ 2, pp. 110 y 111).

No obstante, reconoce que el desempleo es cada vez en mayor medida un «problema femenino» y también hay grandes diferencias en cuanto al salario percibido por hombres y mujeres, pero esto último sería responsabilidad de los agentes sociales: patronal y sindicatos. De continuo sostiene que los «avances positivos» se han realizado en los «últimos años».

Igualmente y aun cuando reconoce la menor presencia de mujeres en puestos de responsabilidad y de decisión «se ha producido una mejora respecto a la situación de partida....» (Ministro de Trabajo, Comisión Mixta de los Derechos de la Mujer, Sesión n. ${ }^{\circ}$ 2, pp. 115).

Asimismo reconoce otras esferas que son prioritarias para el Gobierno, tal y como la violencia doméstica, que se materializa en la aprobación de un plan contra la violencia doméstica para el período 1998-2000 "plan que se está desarrollando en la actualidad con un altísimo grado de ejecución» (Ministro de Trabajo, Comisión Mixta de los Derechos de la Mujer, Sesión n. ${ }^{\circ}$ 2, pp. 116).

Concluye la intervención con un reconocimiento de lo que aún falta por hacer, pero de nuevo da muestras de optimismo con palabras de ofrecimiento, colaboración y consenso para avanzar en el camino hacia la igualdad.

«El camino está iniciado pero aún queda mucho trecho y no carente de dificultades; sin embargo estoy convencido de que entre todos, hombres y mujeres, podemos ir avanzando hasta alcanzar la tan ansiada igualdad real de oportunidades. En este camino, señorías, estoy seguro de contar con su apoyo, y reitero la disposición del Ministerio de Trabajo y Asuntos Sociales para desarrollar su actuación desde el más amplio consenso y desde la más leal colaboración" (Ministro de Trabajo, Comisión Mixta de los Derechos de la Mujer, Sesión N.2, pp. 116). 
Tras la comparecencia del Ministro intervienen los portavoces de los grupos parlamentarios, para hablar en respuesta a lo que ha dicho el Ministro. Es común a todos ellos que den muestra de lo que anteriormente se definí como cortesía parlamentaria, puesto que con independencia del partido y género del interviniente, todos ellos inician su intervención con palabras de gratitud y agradecimiento al Ministro por su comparecencia ante la Comisión y cierran la intervención poniéndose, en nombre de su grupo parlamentario, a disposición del Gobierno, para avanzar en el camino hacia la igualdad, si bien realizarán "crítica constructiva» en aquellos aspectos que entiendan que pueden mejorarse.

Ahora bien, las demandas de los grupos parlamentarios, varían en función del género del interviniente y del partido político de procedencia, pues van desde solicitudes de actuaciones claras y concretas en ámbito específicos, empleando un lenguaje más o menos crítico, (ver el ejemplo de Izquierda Unida) hasta felicitaciones por la labor realizada por el Gobierno al que representa el Ministro en materia de igualdad (el caso de la Portavoz del Partido Popular).

«Nosotros, desde el Grupo Parlamentario Socialista, le animamos a que tome medidas valientes y contundentes, medidas específicas que atajen las situaciones concretas, porque a las mujeres «se nos oculta en los datos globales, como por ejemplo, las mujeres mayores de 45 años que tienen más problemas a la hora de acceder al empleo». (Mujer, PSOE, Comisión Mixta de los derechos de la mujer, sesión $\mathrm{N}^{\circ}{ }^{\circ}$, pp. 118).

«Me gustaría que especificara más las propuestas de su Ministerio para incrementar la red de atención a la infancia y a las personas dependientes». (Mujer, PSOE, Comisión Mixta de los Derechos de la Mujer, sesión n. ${ }^{\circ}$ 2, pp. 118).

«Me gustaría sugerirle que el próximo Plan contra la violencia, se hiciera con partidas presupuestarias concretas y especificas para cada una de las medidas, porque eso ayuda a a hora de poder evaluar dicho plan». (Mujer, PSOE, Comisión Mixta de los Derechos de la Mujer, sesión n. ${ }^{\circ} 2$, pp. 118).

«Señor Ministro, la constatación de que estamos avanzando, de que estamos en definitiva en el buen camino, no impide que seamos conscientes de lo mucho que queda todavía por hacer. (Mujer, CIU, Comisión Mixta de los Derechos de la Mujer, sesión n. ${ }^{\circ} 2$, pp. 120).

«Desearíamos saber si tiene prevista la campaña de «tolerancia cero» para potenciar el rechazo social a los agresores y, en caso afirmativo, en que consistiría» (Mujer, CIU, Comisión Mixta de los Derechos de la Mujer, sesión n. ${ }^{\circ}$ 2, pp. 121).

«Respecto a los recursos, hay dos cuestiones pendientes, desde nuestro punto de vista: el fondo de garantías de pensiones y las pensiones de viudedad. (Mujer, CIU, Comisión Mixta de los Derechos de la Mujer, sesión n. ${ }^{\circ}$ 2, pp. 121).

«...No solo hay que describir, sino también recetar y dar trigo y, por tanto, adoptar las medidas oportunas para abordar los problemas, respecto de los que todos podemos estar de acuerdo en su descripción...» (Varón, Grupo Parlamentario Mixto, Comisión Mixta de los Derechos de la Mujer, sesión n. ${ }^{\circ}$ 2, pp. 120).

«...cuidado con las ideas que se tienen respecto a lo bien que van las cosas...». (Varón, Grupo Parlamentario Mixto, Comisión Mixta de los Derechos de la Mujer, sesión n..$^{\circ}$, pp. 123). 
«.... hacen falta medidas de carácter garantista que permitan el ejercicio y la concreción de esa igualdad de oportunidades y derechos de la mujer. Por tanto creo que habría que adoptar algunas medidas más concretas, más precisas, aunque figuren ya en los programas y la filosofía que usted, señor Ministro ha planteado...» (Varón, Grupo Parlamentario Mixto, Comisión Mixta de los Derechos de la Mujer, sesión n. ${ }^{\circ}$ 2, pp. 122).

«... no sólo es conveniente describir la realidad, sino cambiarla, y para eso estamos aquí, para intentar cambiar la realidad que nos rodea, si no estaríamos en la conformidad más absoluta...». (Varón, Grupo Parlamentario Mixto, Comisión Mixta de los Derechos de la Mujer, sesión n. ${ }^{\circ}$ 2, pp. 123).

«No voy a entrar en guerras de cifras porque es absurdo, pero hay una cuestión que sí quiero decir al Ministro, y es que una cosa es el diagnóstico, otra el pronóstico y otra muy distinta el tratamiento. Coincidimos en el diagnóstico pero Señor Ministro, en el pronóstico hay plazos. Cuando un médico dice qué enfermedad tiene uno, ha hecho un diagnóstico, pero cuando dice qué posibilidades tiene uno de seguir adelante con esa enfermedad está entrando en el pronóstico. Eso es lo que yo quiero saber, qué pronóstico tiene el Partido Popular para el colectivo de las mujeres en su conjunto, para las españolas, y, por supuesto, qué tratamiento piensa aplicar para remediar nuestro mal. (Mujer, Izquierda Unida, Comisión Mixta de los Derechos de la Mujer, sesión n. ${ }^{\circ}$ 2, pp. 124).

«Háblemos usted de plazos, de calendarios, de presupuestos y a lo mejor encontramos las diferencias que desgraciadamente o afortunadamente no aparecen en esta sesión, pero existen...». (Mujer, Izquierda Unida, Comisión Mixta de los Derechos de la Mujer, sesión n. ${ }^{\circ}$ 2, pp. 124).

«... como mujer, como feminista y como parlamentaria, voy a ser beligerante en todo lo que tenga que ver con la vida de las mujeres...» (Mujer, Izquierda Unida, Comisión Mixta de los Derechos de la Mujer, sesión n. ${ }^{\circ}$, pp. 124).

«... sepa que no me voy a conformar con literatura o con planes de igualdad que no tienen presupuestos ni calendario detrás..." (Mujer, Izquierda Unida, Comisión Mixta de los Derechos de la Mujer, sesión n. ${ }^{\circ}$, pp. 125).

«... hemos de solucionar pronto aquello que tenga un fundamento económico, de forma que se vea reflejada nuestra voluntad de arreglar los problemas puntuales que tanto afectan al colectivo de la mujer, discutir sobre los objetivos a largo plazo y sopesar los planes puntuales que se vayan presentando...». (Mujer, Entesa Catalana de Progrès. Comisión mixta de los Derechos de la Mujer, Sesión N. 2, pp. 125).

«... Tenemos una ley de conciliación ente la vida familiar y laboral, pero mientras no hagamos ver a los integrantes del ámbito familiar que incluso dentro de la propia familia hay que conciliar y repartir las taras, difícilmente las mujeres vamos a poder conciliar la vida familiar y laboral....» (Mujer, Partido Nacionalista Vasco, Comisión Mixta de los Derechos de la Mujer, sesión n.2, pp. 126).

«... la violencia hay que abordarla de forma global, teniendo en cuenta el entorno en que ésta se produce.....» (Mujer, Partido Nacionalista Vasco, Comisión Mixta de los Derechos de la Mujer, sesión n. ${ }^{\circ}$ 2, pp. 127).

«... El Grupo Popular valora de forma positiva la gestión que el Gobierno ha venido realizando de forma eficaz a lo largo de estos más de cuatro años en el área de la Igualdad de Oportunidades y, genéricamente, en el área de la mujer...» (Mujer, Partido Popular, Comisión Mixta de los Derechos de la mujer, Sesión n. ${ }^{\circ}$, pp. 127). 
«Hemos vivido los cuatro mejores años de la seguridad social y alrededor de 1.200.000 mujeres se han afiliado a la misma en estos últimos años, lo cual supone seguridad para el presente y bienestar y mucha más seguridad para el futuro....». (Mujer, Partido Popular, Comisión Mixta de los Derechos de la Mujer, sesión n. ${ }^{\circ}$, pp. 128).

«... Le animamos a seguir con las medidas de política de integración y empleo de la mujer...» (Mujer, Partido Popular, Comisión Mixta de los Derechos de la Mujer, Sesión n. ${ }^{\circ}$ 2, pp. 128).

«... Resulta satisfactorio escuchar que el Gobierno elaborará un nuevo plan de acción integral contra la violencia...» (Mujer, Partido Popular, Comisión Mixta de los Derechos de la Mujer, Sesión N. ${ }^{\circ}$, pp. 129).

Del análisis realizado de la Sesión N.$^{\circ} 2$ de la Comisión Mixta de los Derechos de la mujer podrían destacarse las siguientes conclusiones. En primer lugar y siguiendo la propuesta de Dalherup en la que se destacaba la relación entre la presencia femenina en sedes parlamentarias y la presencia de una agenda y un estilo político de género, en esta Comisión donde todos los portavoces de los grupos parlamentarios son mujeres excepción hecha del portavoz del Grupo Parlamentario Mixto, parece que las mujeres desarrollan un estilo político propio, caracterizado por el uso de un «lenguaje directo y sin rodeos», demandando soluciones claras y concisas a problemas concretos y con actitudes críticas y de inconformismo conforme crece la distancia ideológica entre el partido al que representan y el partido del compareciente en la Comisión. Además, parece que los partidos de la izquierda centran más sus demandas en aspectos sociales y de atención y cuidado a «sectores débiles» de la población (infancia, personas mayores, medidas para controlar al agresor), así como demanda de medidas educativas y de formación; mientras que según se avanza hacia la derecha del espectro ideológico, las demandas adquieren matices económicos y de colaboración interinstitucional (presupuesto invertido, competencias de las Comunidades autónomas en materia de igualdad etc.).

\subsection{Comisión de Educación, Cultura y deporte: Debate y votación de proposiciones no de ley según género y partido político}

Dentro de la Comisión de Educación. Cultura y deporte, se ha analizado el contenido de la sesión $n{ }^{\circ} 18$ celebrada el miércoles 13 de junio de 2001 que tenía como orden del día el debate y votación de un total de siete proposiciones no de ley. La composición de la Comisión responde, siguiendo la terminología de Dalherup a «grupos equilibrados», pues en su composición por género, se da una relación entre subgrupos cercana a la mitad 60:40, de donde cabría suponer que cada grupo tendría una agenda y un estilo político propio, puesto que las mujeres al no constituir en esta Comisión un grupo minoritario no tendrían que adoptar estrategias adaptativas a las reglas, normas, agenda o estilo del grupo predominante -tradicionalmente los varones-.

Como se observa en la tabla 5 , son las mujeres las que introducen en la agenda política temas de género, como es el fomento de la participación de la mujer en el deporte femenino, así como preocupaciones relativas a aspectos 


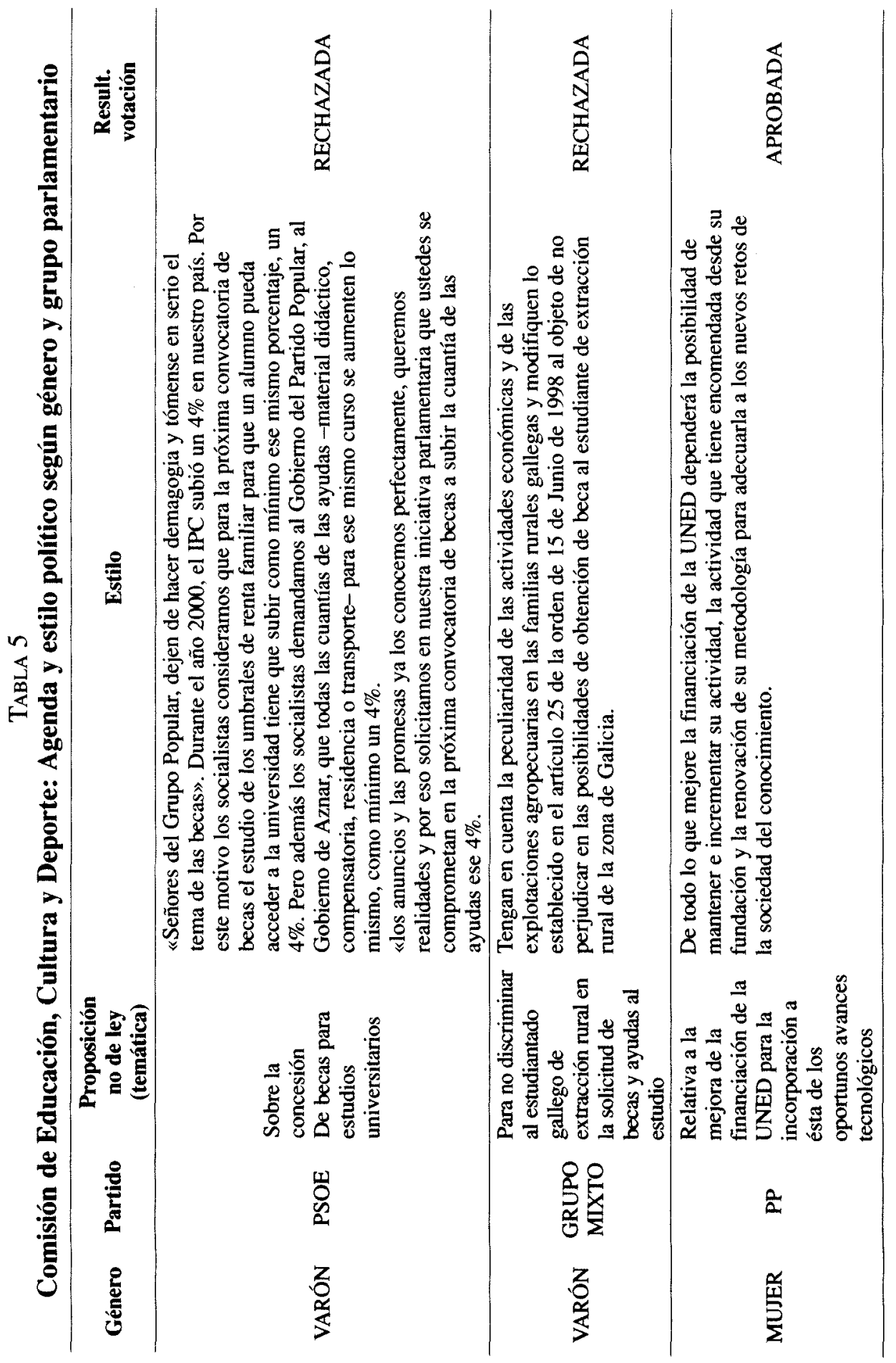


EL ESTILO POLÍTICO DE LA CLASE PARLAMENTARIA ESPAÑOLA: PROPUESTA...

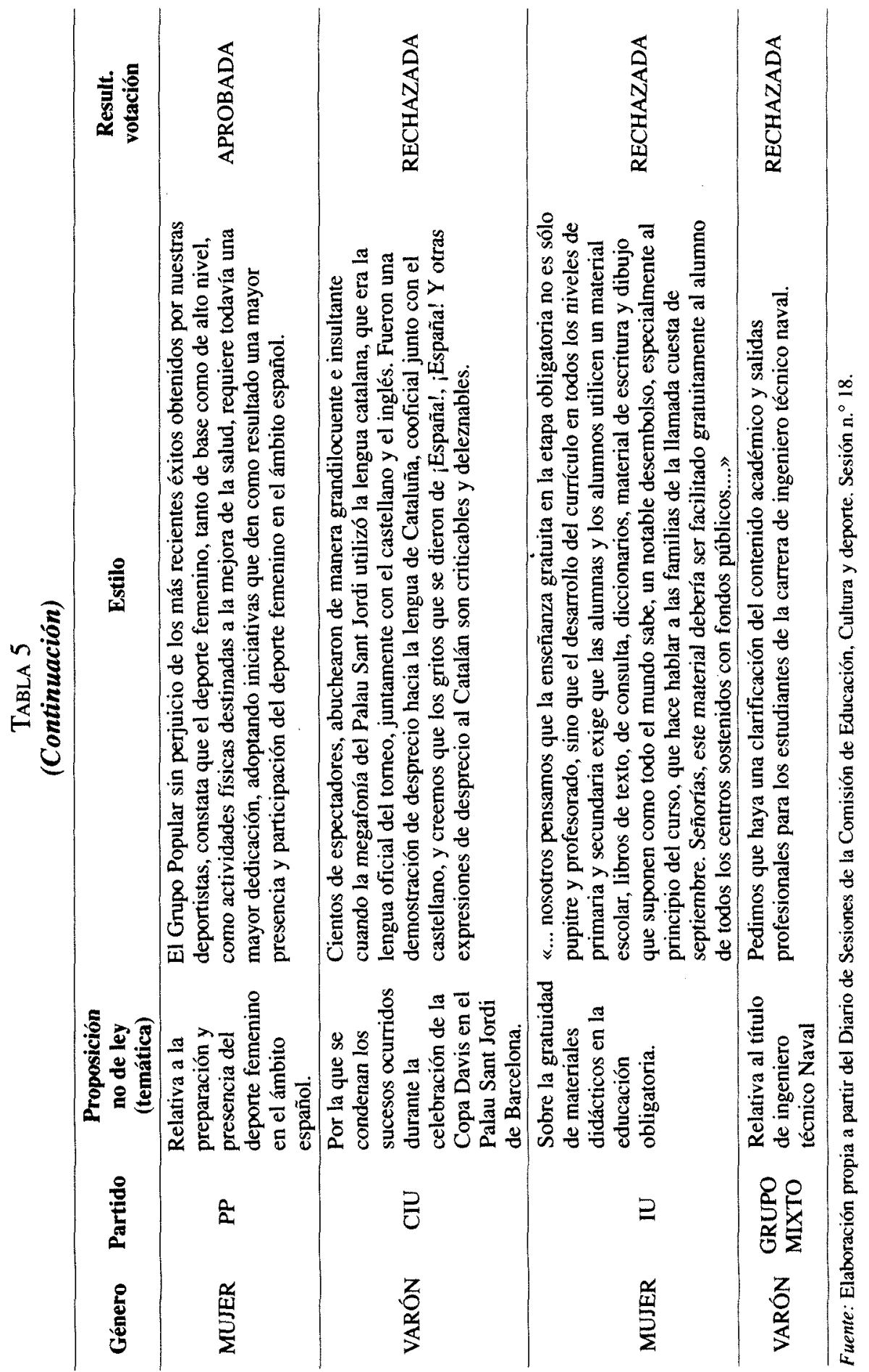


que redunden en la mejora de la calidad de la enseñanza, bien por la introducción de avances tecnológicos bien por el deseo de hacer extensible la gratuidad de la enseñanza en todas sus dimensiones, incluyendo los materiales didácticos, que redunden de manera directa en el sujeto benefactor de la medida de que se trate. En cambio los varones centran su atención en aspectos de carácter más económico (subvenciones, becas) y problemas que atentan contra la libertad de expresión linguística. Dicho de otro modo, las mujeres presentan una agenda política más centrada en aspectos sociales, varones aspectos económicos.

\subsection{Comisión de infraestructuras: ¿Agenda y estilo político masculino?}

La última Comisión de la que se hará un somero análisis de contenido se caracteriza, por estar integrada mayoritariamente por varones. Ello haría, siguiendo la terminología de Drude Dalherup, que los grupos minoritarios, las mujeres, desarrollaran estrategias adaptativas en cuanto al modo y ejercicio de la política, de manera que seguirían las normas y reglas del grupo dominante, lo que dificultaría el desarrollo de una agenda y un estilo político propio. En concreto se centra el análisis en el contenido de la sesión n.$^{\circ} 20$ celebrada el martes 12 de Junio de 2001 en el Palacio del Congreso de los Diputados. El orden del día de la sesión se centra en tres puntos fundamentales. El primero de ellos se centra en una serie de preguntas formuladas a diversos miembros de la Administración del Estado sobre temas relacionados con el trabajo de la Comisión. El segundo supone la comparecencia del señor secretario de Estado de Infraestructuras para informar sobre el proceso de adjudicación de material móvil de alta velocidad para la línea Madrid-Barcelona por parte de Renfe. El tercer y último punto tiene como objetivo el debate y votación de un total de nueve proposiciones no de ley.

$\mathrm{Al}$ objeto de no hacer demasiado extenso este trabajo, y puesto que en este último apartado tan sólo es un primer acercamiento al modo de ejercicio de la política por la clase parlamentaria española mediante el análisis de los trabajos realizados en tres Comisiones, el análisis se centrará como viene siendo habitual en una descripción somera de las propuestas, preguntas y proposiciones según el género del interviniente, para ver si cabe hablar de agendas y estilo políticos diferentes según sean varones o mujeres quienes intervienen en las discusiones dentro de la Comisión.

La tabla 6 se recogen las diferentes preguntas que los portavoces de los distintos grupos Parlamentarios formulan, en este caso, al Secretario de Estado de Infraestructuras. Como puede comprobarse se formulan un total de nueve preguntas, tan sólo una de ellas la formula una mujer. Además, las preguntas, cabe pensar que determinadas en parte por los temas de trabajo propios de la Comisión, guardan relación fundamentalmente con aspectos económicos relativos a construcción y dotación de infraestructuras, gestión de espacios, inversión económica y calendarización prevista para la ejecución y mejora de diversas obras relacionadas con el transporte aéreo y por carretera. 
EL ESTILO POLITICO DE LA CLASE PARLAMENTARIA ESPAÑOLA: PROPUESTA...

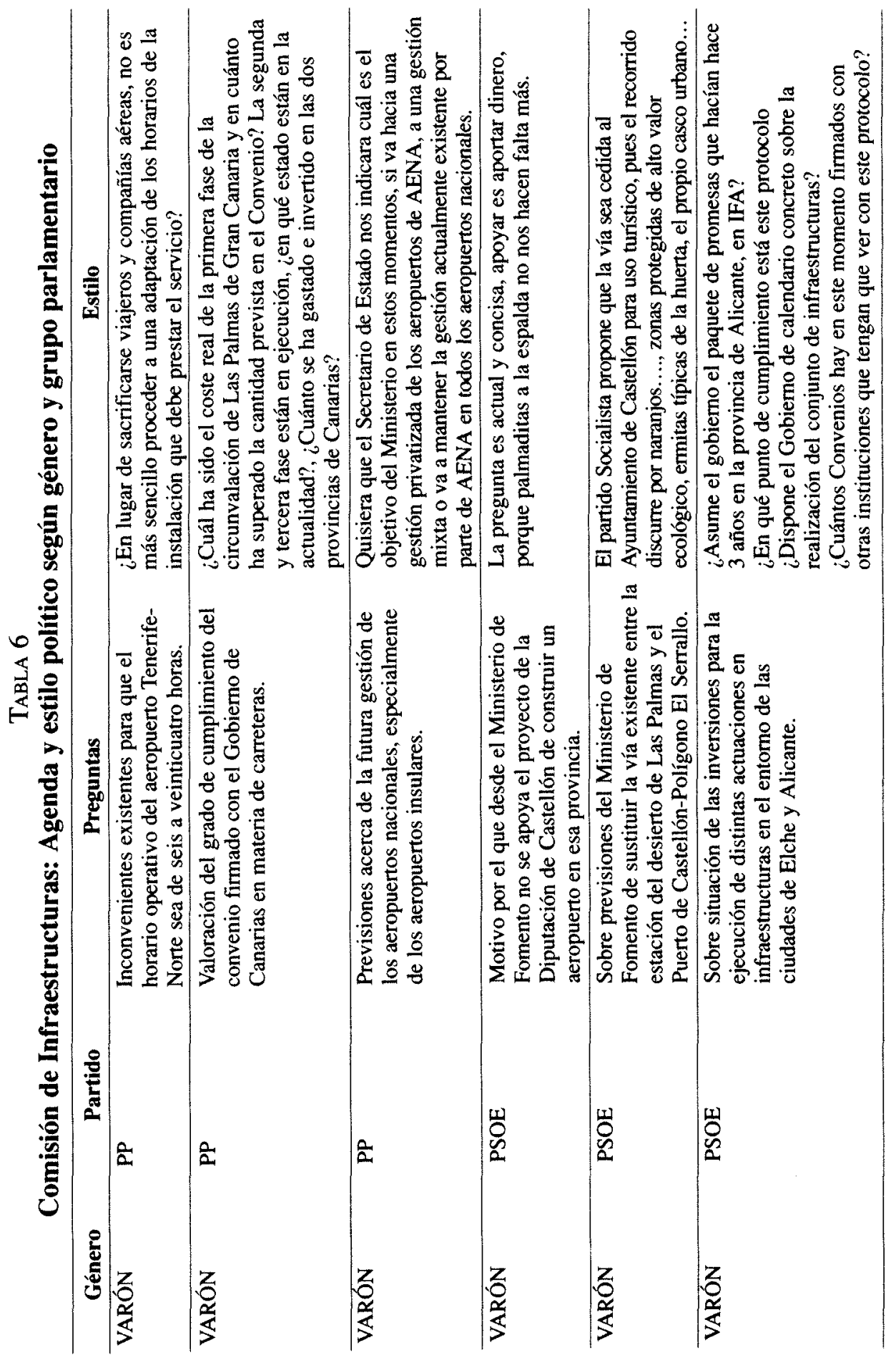




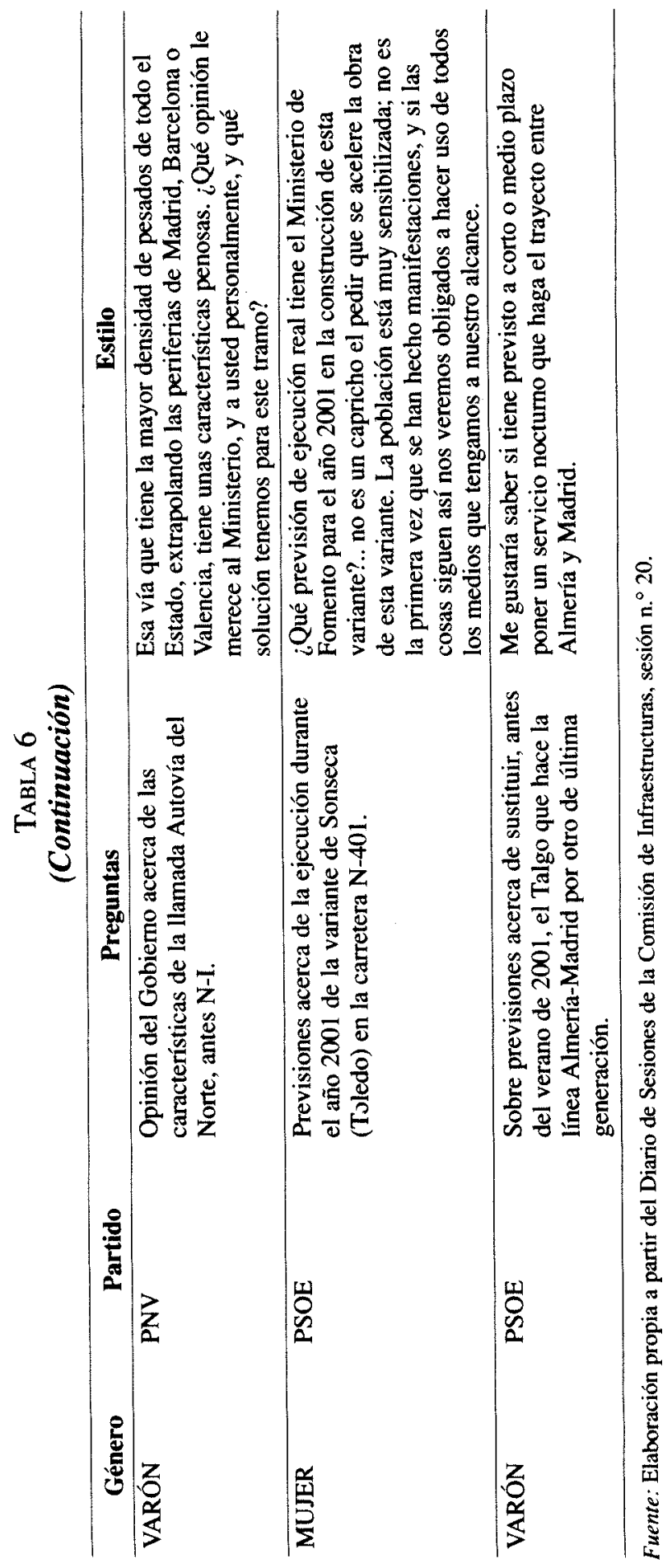


EL ESTILO POLÍTICO DE LA CLASE PARLAMENTARIA ESPAÑOLA: PROPUESTA...

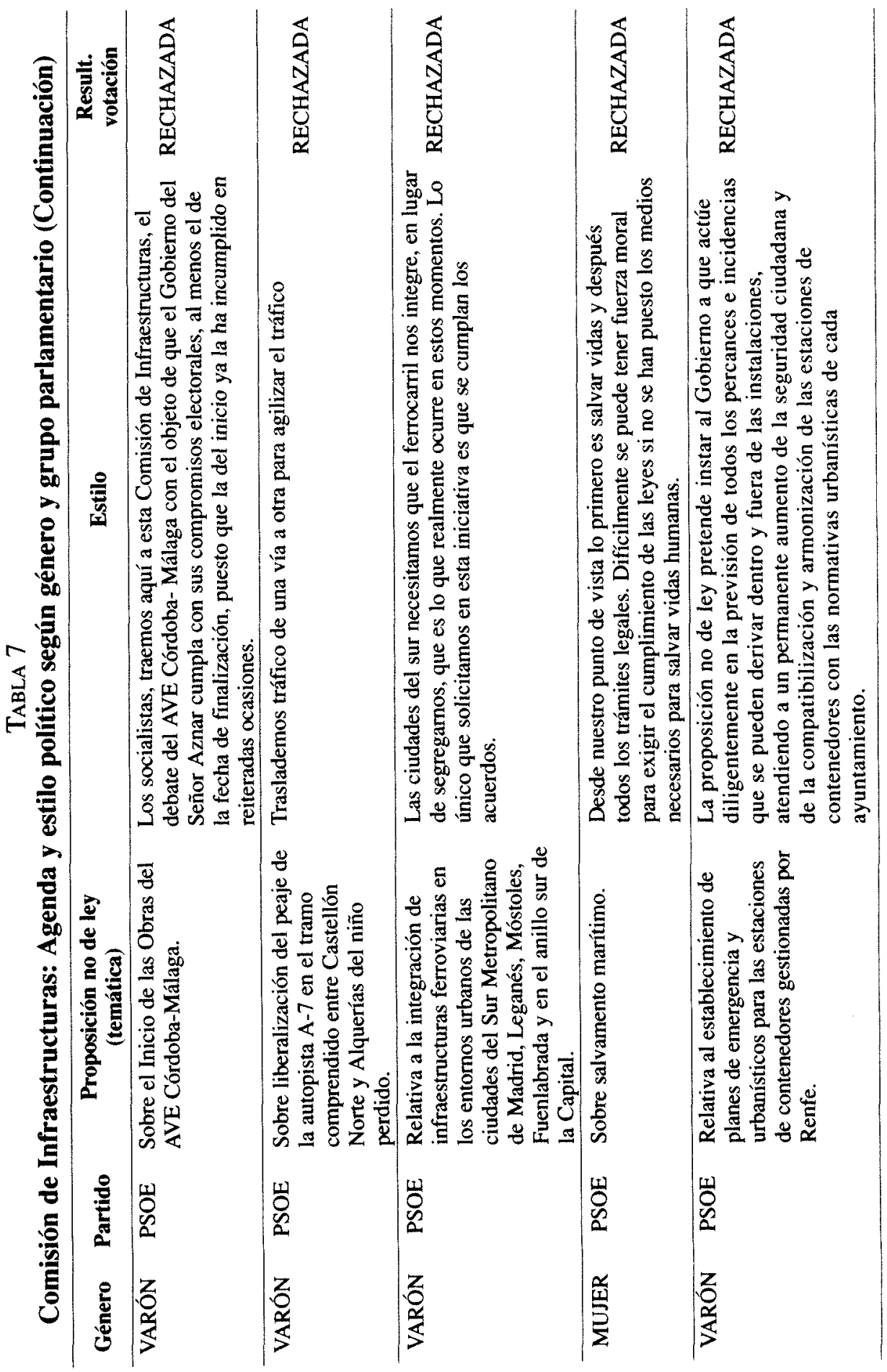




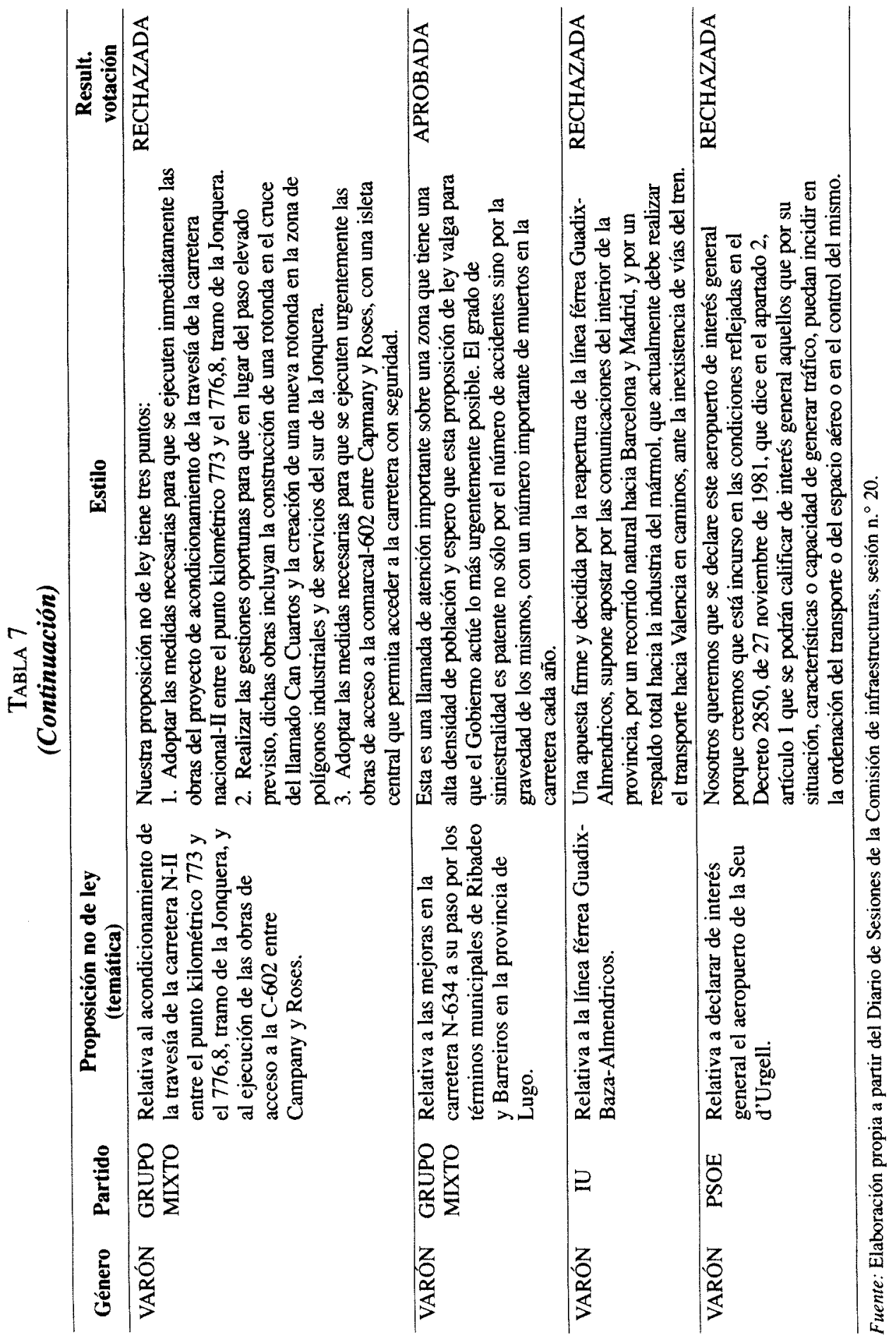


Por otra parte se sometieron a debate y votación un total de 9 proposiciones de no ley. Como se observa en la tabla 7 tan sólo dos fueron presentadas por mujeres, ambas del partido socialista. Por el contenido de las proposiciones se observa que en general, al igual que sucediera en las preguntas, se centran en aspectos relativos a mejora de infraestructuras ferroviarias o de la red de carreteras, y de calendarización prevista para la ejecución de diversas obras, en definitiva aspectos económicos y de mejora de la calidad de vida. Por otra parte, se introducen temas sociales, dirigidos a la atención y cuidado de los demás en la proposición no de ley relativa al salvamento marítimo, en la que se hace referencia al problema de los inmigrantes, $y$ en la proposición planteada por el grupo parlamentario mixto en relación con la mejora de las carreteras en la provincia de Lugo dada la alta siniestralidad que viene padeciendo.

\section{CONCLUSIONES}

En este trabajo se ha intentado elaborar una propuesta metodológica dirigida al estudio del modo de ejercicio de la política por parte de la clase parlamentaria española. A partir de la terminología de Drude Dalherup donde destacaba la relación entre la presencia femenina en las sedes parlamentarias y la génesis y desarrollo de un estilo político femenino, se ha intentado aplicar al caso de España, tomando como estudio de caso tres Comisiones, cada una de las cuales presentaba una muy distinta composición según géneros. El análisis es meramente exploratorio y tentativo, por lo que para llegar a conclusiones que estuvieran dotadas de validez científica hubiera sido necesario realizar un análisis mucho más depurado, fino y cuidadoso y atendiendo a otros muchos factores que pudieran influir en el desarrollo de una agenda y estilo político femenino diferente al masculino, como pudiera ser el partido político de procedencia, el contexto institucional, las relaciones entre actores etc. Por otra parte, como se dijo más arriba, resulta una tarea complicada analizar el modo de ejercicio de la política puesto que ciertas reglas procedimentales limitan la capacidad de actuación de la clase política, y, por otra parte, el «lenguaje político» aparece impregnado de ciertas normas no escritas de «cortesía parlamentaria» que hacen difícil captar las relaciones entre los miembros de la élite política y la forma en que tienen de tratar los diferentes temas que abordan en las distintas Comisiones. Ello lleva a que resulte necesario entrelazar análisis de contenido y análisis del discurso político, junto con la aplicación de otras técnicas de investigación como entrevistas en profundidad que permitan conocer la percepción subjetiva en torno al estilo político por parte de los propios actores políticos.

Como se recoge en la figura 3 , de los análisis realizados pudiera sostenerse que las mujeres tienden a presentar una agenda política centrada en aspectos sociales de atención y cuidado de los demás, con un lenguaje directo, conciso y demandando actuaciones concretas, mientras que los varones se centran más en aspectos económicos, en torno a inversiones, subvenciones o infraestructuras. No obstante estas aseveraciones merecen ser contrastadas en posteriores análisis, donde mediante el desarrollo de procesos de triangulación metodológica, se pueda determinar el peso de la presencia femenina en la génesis y desarrollo de una agenda política de género. 


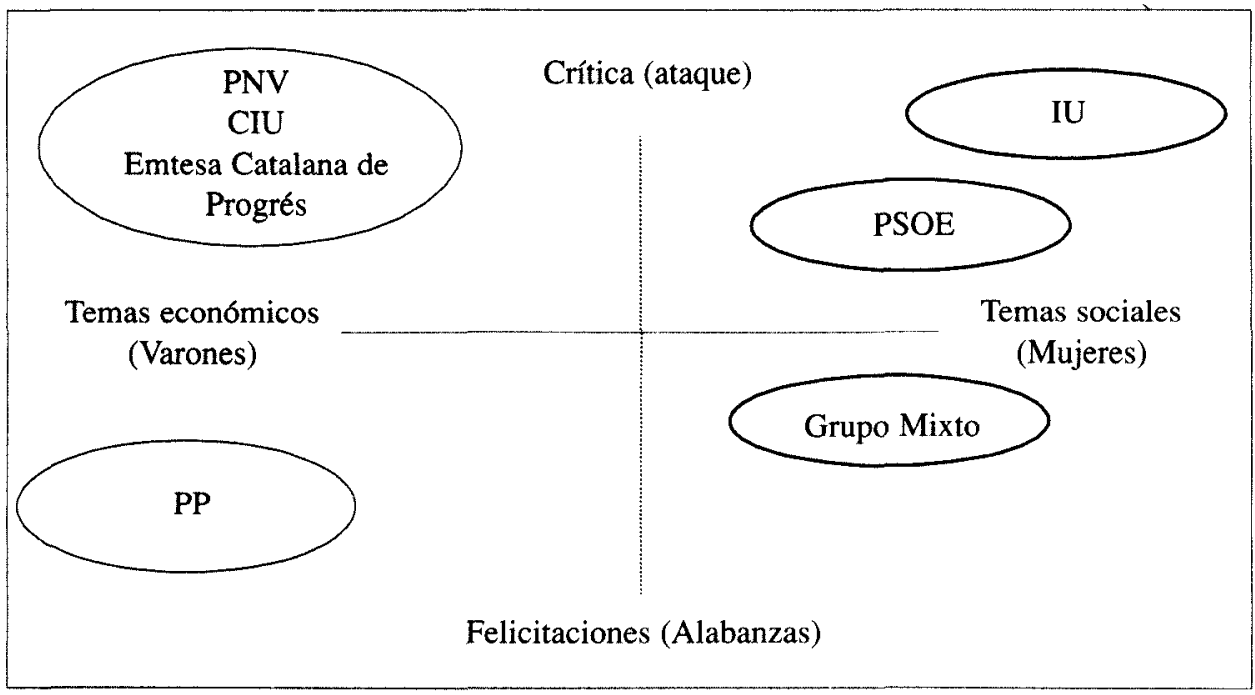

FIGURA 3. Género, Agenda y estilo político de la Clase Parlamentaria Española (VII Legislatura).

\section{REFERENCIAS BIBLIOGRÁFICAS}

Astin, H.S y Leland, C (1991): Women of influence, women of division, San Francisco: Jossey-Bass.

Bustos, R (2000): «La función legislativa», en Martínez, A (Edit): El Congreso de los Diputados en España: funciones y rendimiento, Madrid, Tecnos, pp. 37-68.

DALHERUP, D. (1988): «From a small to a large Minority: Women in Scandinavian Politics», en Scandinavian Political Studies, N. ${ }^{\circ} 11$ (4), pp. 275-298.

FrASER, N. y GORDON, L. (1992): «Contrato versus caridad: una reconsideración de la relación entre ciudadanía civil y ciudadanía social», en Isegoría, N ${ }^{\circ} 6$, pp. 65-82.

Genovese, M.A. (1997): Mujeres líderes en política, modelos y prospectiva, Madrid, Narcea.

KyMLICKA, W. (1995): Filosofía política contemporánea, Barcelona, Ariel.

PITKIN (1985): El concepto de representación, Madrid, CEC.

SAPIRO, V.(1981): «When are Interests Interesting?»,American Political Science Review, $75(3)$.

URIARTE, E. (1997): «Estudios de mujer y política en España», en Uriarte, E. y Elizondo, A. (coord.): Mujeres en política, Barcelona, Ariel, pp. 15-32.

WAERNESS, K. (1987): «sobre la racionalidad del cuidado», en Showstack, A. (ed.): Las mujeres y el estado, Madrid, Vindicación feminista, pp. 241-272. 